\title{
Natural and Synthetic Isothiocyanates Possess Anticancer Potential Against Liver and Prostate Cancer In Vitro
}

\author{
EMILY CROWLEY ${ }^{1}$, NEIL J. ROWAN ${ }^{1}$, DON FALLER $^{2}$ and ANNE M. FRIEL ${ }^{1,2}$ \\ ${ }^{1}$ Bioscience Research Institute, Athlone Institute of Technology, Athlone, Ireland; \\ ${ }^{2}$ Department of Life and Physical Science, Athlone Institute of Technology, Athlone, Ireland
}

\begin{abstract}
Background/Aim: Isothiocyanates (ITCs) are phytochemicals with potential cancer-preventative properties derived from the breakdown of glucosinolates that exist in cruciferous vegetables. Studies, to date, have demonstrated that various ITCs possess the ability to act as anticancer agents in different cancer types. This study investigated the anticancer properties of dietary ITCs (allyl-ITC, benzyl-ITC, phenylethyl-ITC) and synthetic (phenylbutyl-ITC and phenylhexyl-ITC) on liver and prostate carcinoma cells in vitro. Materials and Methods: The effects of ITCs on cellular viability, migration, invasion, clonogenicity, apoptosis induction and reactive oxygen species generation were assessed in HepG2, DU145 and 22Rv1 cells. Results: All ITCs reduced metabolic activity in each cell line with the most significant being phenylethyl-ITC. Both dietary and synthetic ITCs suppressed the migratory and invasive potential of all cell lines, inhibited colony-forming capability and induced apoptosis. Phenylethyl-ITC exposure resulted in the significant generation of reactive oxygen species. Conclusion: These data highlight the potential advantages of utilizing ITCs to delay the carcinogenic process and the potential for dietary and synthetic ITCs to act as anticancer agents.
\end{abstract}

"Cancer is a complex manifestation of genomic instability in cells caused by environmental or genetic factors" (1). This instability results in an alteration of essential biological operations, such as cell division, leading to cancer. Initial alterations such as mutations and deletions occurring at the genomic level can become translated into structural changes within cells and tissues and further uncontrolled proliferation

This article is freely accessible online.

Correspondence to: Anne M. Friel, Dept. Life and Physical Science, Athlone Institute of Technology, Dublin Rd, Bunnavally, Athlone, Co. Westmeath, Ireland. E-mail: afriel@ait.ie

Key Words: Glucosinolates, isothiocyanates, liver cancer, prostate cancer, clonogenicity, invasion, apoptosis. of the altered cells may result in tissue modifications (2), e.g. the transformation of a normal cell into a malignant cell (3). Cancer development encompasses the three stages of carcinogenesis: initiation, progression and promotion (4). On average, there are 40,000 new cancer diagnoses each year in Ireland and it is believed that by 2020 , half of the population will develop cancer during their lifetime. Cancer-related deaths account for $30 \%$ of all deaths annually, making it the biggest killer of the Irish population (5).

Cancer of the liver, also known as hepatocellular carcinoma (HCC) is one of the most common causes of death worldwide. The most recent cancer projections for Ireland (2010 to 2040) indicate that cases of liver, biliary tract and gallbladder cancer will increase by $127-148 \%$ in women and by $113-155 \%$ in men (6). Prostate cancer is the second most common cancer in Ireland, with statistics highlighting that one in every eight men are diagnosed with this form of cancer during their lifespan (7).

Studies have shown direct correlations between an increase in cruciferous vegetable intake and the reduced risk of cancer (8) and that an increase in the consumption of these vegetables may have a cancer chemoprotective effect (9). The cancer chemoprevention concept involves the use of natural or synthetic chemicals to inhibit, reverse or slow down the cancer process to prevent invasive cancer (2). This is greatly believed to be as a result of dietary components such as glucosinolates (10). Glucosinolates are thioglucoside compounds that occur naturally in a range of cruciferous vegetables such as brussel sprouts, cabbage and broccoli (11). Myrosinase, an enzyme that co-exists with each isothiocyanate precursor in plant cells, catalytically mediates the generation of isothiocyanates (ITCs) from their corresponding glucosinolate precursor after cruciferous plant damage, allowing its release (12).

Numerous studies, to date, have demonstrated the anticancer effect of crucifers in both in vitro and in vivo experiments and it is believed that sub-toxic concentrations of glucosinolate metabolites (i.e. ITCs) are responsible for carcinogenic inhibition observed after exposure (13). Additionally ITCs have been demonstrated to retard or prevent the growth of tumour cells in vitro and in vivo (14). There are 
various ITCs, some of which include allyl-ITC (AITC), found in cabbage, benzyl-ITC (BITC) and phenylhexyl-ITC (PHITC) found in watercress, and sulforphane in broccoli and cauliflower (4). ITCs have strong bioactivity and their therapeutic potential is consistently being examined (15).

The present study was designed to determine the anticancer potential of both short-(naturally occurring) and long-(synthetically manufactured) chain ITCs against liver and prostate cancer. To date, it has been shown that ITC activity varies with ITC chain length, with some studies demonstrating an increased potency with a longer chain length, while other studies showing a reduced effect $(16,17)$. Other studies have demonstrated that the chemopreventative efficacy of an ITC is influenced by its number of carbons $(18,19)$. Lui et al. noted that slight structural differences between ITCs can dramatically affect their anticancer potential (20).

Therefore, in this study five ITCs with different alkyl chain lengths were selected for anticancer analysis against both liver and prostate cancer cells in vitro. The studies were carried out with three short-chain ITCs that are found in vegetables: AITC, BITC and phenylethyl-ITC (PEITC). Investigative studies into the anticancer potential of synthetic long-chain ITCs involved two man-made ITCs, phenylbutylITC (PBITC) and phenylhexyl-ITC (PHITC). All ITCs were assessed for anticancer potential against HepG2 liver cancer cell line, and two prostate cancer cell lines, androgendependent 22Rv1 and androgen-independent DU145, in vitro.

\section{Materials and Methods}

Chemicals and cell culture. The HepG2 cell line was obtained from the American Type Culture Collection (Manassas, VA, USA). DU145 and 22Rv1 were obtained from Professor L. O'Driscoll, Trinity College Dublin, Ireland. HepG2 cells were maintained in Dulbecco's modified Eagle's medium (DMEM; Gibco, Dublin, Ireland) supplemented with $10 \%$ foetal bovine serum (FBS; Gibco), $1 \%$ penicillin/streptomycin (Sigma-Aldrich, Wicklow, Ireland) and $1 \%$ L-glutamine (Sigma-Aldrich). DU145 and 22Rv1 cells were maintained in Roswell Park Memorial Institute (RPMI-1640) medium containing $10 \% \mathrm{FBS}, 1 \%$ penicillin/streptomycin and $1 \%$ L-glutamine (Sigma-Aldrich). All cell lines were cultured at $37^{\circ} \mathrm{C}$ with $5 \% \mathrm{CO}_{2}$.

Isothiocyanates. BITC, AITC and PEITC were purchased from Sigma-Aldrich. PBITC and PHITC were purchased from Abcam (Cambridge, UK).

Cell viability assay. Cells were seeded at a density of $1 \times 10^{5 / 100} \mu \mathrm{l}$ per well of a 96-well plate. After overnight cell adherence and growth, cells were treated with increasing concentrations of ITCs $(0$, $2.5,5,10,15 \mu \mathrm{M})$. The initial dilution of the ITCs was carried out in dimethyl sulfoxide (DMSO) and subsequent dilutions were carried out in growth media. The final concentrations of DMSO in the culture media for ITC treatment was controlled to less than $0.1 \%$. Two incubation periods were carried out for ITC treatment of the cancer cells, $24 \mathrm{~h}$ and $48 \mathrm{~h}$. After the desired incubation duration, ITC-containing media were removed, and cells were treated with $10 \%$ 3-(4,5-dimethylthiazol-2-yl)-2,5-diphenyltetrazolium bromide (MTT) in DMEM for $3.5 \mathrm{~h}$ at $37^{\circ} \mathrm{C}$ in a humidified incubator with $5 \% \mathrm{CO}_{2}$. After $3.5 \mathrm{~h}$, the MTT and media were removed and discarded, and the converted blue formazan product was solubilized from the cells through the addition of $100 \mu \mathrm{l}$ of DMSO per well. Solubilized product was quantitatively measured at $540 \mathrm{~nm}$ using an enzyme-linked immunosorbent assay (ELISA) plate reader. Results were expressed as percentage viability.

Clonogenicity assay. Also known as the colony-forming assay, this method was utilized to determine the ability of ITC-treated cells to reproduce and form colonies after ITC exposure (21). Cells were seeded at a very low density of $5 \times 10^{3}$ per well of a 6 -well plate with a final volume of $3 \mathrm{ml}$. Cells were left to adhere overnight at $37^{\circ} \mathrm{C}$ before sublethal ITC treatment $(0,2.5,5,10 \mu \mathrm{M})$ for $24 \mathrm{~h}$. After $24 \mathrm{~h}$ ITC treatment, cells were washed and incubated with fresh supplemented DMEM or RPMI-1640 (depending on cell line) and the media were changed every 2 days before fixing, staining and photographing the colonies formed on day 7 post-ITC treatment. Glacial acetic acid (33\%) was utilized to solubilize the crystal violet from the colonies and the colony-forming was quantitatively measured by reading at $570 \mathrm{~nm}$ using an ELISA plate reader.

Cell migration assay (wound-healing assay). Cells were seeded at a high density and allowed to adhere at $37^{\circ} \mathrm{C}$ until $100 \%$ confluence had been reached. Cell monolayers were scored using a sterile p200 tip before treatment with $5 \mu \mathrm{M}$ ITC for $24 \mathrm{~h}$. Photographs were taken at time zero and time $24 \mathrm{~h}$ after ITC treatment and the migratory capacity of the cells was quantitatively analysed from the results observed, and expressed as percentage wound closure.

Cell invasion. Cells were seeded at a density of $5 \times 10^{4}$ cells per $500 \mu \mathrm{l}$ complete media into $8 \mu \mathrm{m}$ pore transwell inserts (Corning Incorporated, Flintshire, UK) pre-coated with extracellular matrix (ECM) (SigmaAldrich) in 24-well plates. Cells were allowed to adhere for $4 \mathrm{~h}$. Each well was filled with $500 \mu \mathrm{l}$ complete media. After cell adherence, cells were treated with $5 \mu \mathrm{M}$ ITC prepared in $1 \%$ FBS, $1 \%$ penicillin/streptomycin and $1 \%$ L-glutamine using $1 \%$ FBS growth media containing $0.03 \%$ DMSO as the control. After $72 \mathrm{~h}$ ITC treatment at $37^{\circ} \mathrm{C}$, ITC-containing media were removed and discarded and cell inserts were gently washed using phosphate-buffered saline (PBS)-soaked Q-tips before staining with 1\% crystal violet (SigmaAldrich, Wicklow, Ireland). Crystal violet was solubilized with $33 \%$ glacial acetic acid and quantitatively read at $570 \mathrm{~nm}$. Results were expressed as percentage invasion.

Nuclear staining assay. After treatment of HepG2, 22Rv1 and DU145 cells on coverslips with increasing concentrations $(0,2.5$, $5,10,15 \mu \mathrm{M})$ of ITCs, cells were washed with PBS and fixed using $4 \%$ formaldehyde for $15 \mathrm{~min}$ at room temperature. Coverslips with ITC-treated cells were then stained and mounted onto microscope slides using fluoroshield-4',6-diamidino-2-phenylindole (DAPI) (Sigma-Aldrich). The hallmarks of apoptosis were qualitatively observed through fluorescence microscopy and cells scored for the presence of late apoptosis, nuclear condensation, fragmentation and apoptotic bodies, prior to their apoptotic ratio being analysed quantitatively. 
Measurement of reactive oxygen species (ROS). Intracellular ROS generation was measured utilizing the OxiSelect ${ }^{\mathrm{TM}}$ in vitro ROS/RNS Assay Kit (Cell Biolabs Inc., Cambridge, UK). Based on the recommended cell line seeding density, cells were seeded in 12 well plates and allowed to adhere overnight at $37^{\circ} \mathrm{C}$. For each ITC, a low $(5 \mu \mathrm{M})$ and high $(15 \mu \mathrm{M})$ concentration, based on the ITC viability assay, were investigated for ROS induction. After $24 \mathrm{~h}$ ITC exposure, ITC was removed and ITC treated cells were gently washed with sterile PBS. Cells were removed from the base of the wells using a cell scraper and centrifuged at $400 \times g$ for $5 \mathrm{~min}$. Resultant cell pellets were re-suspended in sterile PBS and a cell count was performed. Each cell suspension was diluted with PBS to $5 \times 10^{5}$ cells $/ \mathrm{ml}$ and spun at $10,000 \times g$ for $5 \mathrm{~min}$ for cell lysate preparation. Cell lysates were analysed qualitatively for ROS production as per assay kit manufacturer's recommendations. All samples were stored on ice for the duration of the assay. Results were expressed as relative fluorescence units (RFUs).

Statistical analysis. Data are presented as the mean \pm standard error of the mean (SEM) using GraphPad Prism 5.3 software (Graphpad Software, Inc., La Jolla, CA, USA). Ordinary one-way ANOVA was used to analyse the variance between groups with the Dunnett multiple comparison test to determine the significant difference between control and treatment groups. A $p$-value of less than 0.05 was considered statistically significant.

\section{Results}

Treatment with ITCs results in a dose-dependent reduction of cell viability. In order to evaluate the effect of ITCs on both liver and prostate cancer viability, cell cytotoxicity assays were carried out with HepG2, DU145 and 22Rv1 cell lines. Carcinoma cells were treated with increasing concentrations $(0-15 \mu \mathrm{M})$ of ITCs for a defined period of time $(24 / 48 \mathrm{~h})$. The colorimetric MTT assay for the assessment of cell metabolic activity was utilized to determine the ability of these ITCs to reduce cellular viability.

Treatment of all three cell lines for $24 \mathrm{~h}$ with PEITC (10 and $15 \mu \mathrm{M})$ resulted in a significant reduction in viability (HepG2 and DU145: $p<0.0001,22 \mathrm{Rv1}: p<0.05)$ when compared to vehicle alone (Figure 1). Similarly, a $48 \mathrm{~h}$ exposure (10 and $15 \mu \mathrm{M})$ resulted in significant reduction in viability of HepG2 and DU145 cells (both $p<0.001$ ). Exposure of the 22Rv1 line to PEITC for $48 \mathrm{~h}$ resulted in a significant reduction in viability at $2.5,5,10$ and $15 \mu \mathrm{M}$ $(p<0.0001)$ when compared to vehicle alone (Figure 1$)$.

Treatment with all ITCs caused a reduction of cellular viability in all three cell lines. Exposure for $48 \mathrm{~h}$ to AITC (15 $\mu \mathrm{M})$ resulted in significant $(p<0.05)$ reduction in viability of HepG2 cells compared to the control but not for $24 \mathrm{~h}$ treatment. Twenty-four hours' exposure to AITC resulted in significant reduction in DU145 viability at $10 \mu \mathrm{M}(p<0.05)$ and $15 \mu \mathrm{M}(p<0.05)$ (Figure $2 \mathrm{~A})$, while $48 \mathrm{~h}$ exposure resulted in a more significant reduction in viability at $15 \mu \mathrm{M}$ $(p<0.0001)$ (Figure 2B). Similarly, to DU145 cells, $24 \mathrm{~h}$ exposure of $22 \mathrm{Rv} 1$ cells to AITC also resulted in a significant reduction in viability at $10 \mu \mathrm{M}(p<0.05)$ and $15 \mu \mathrm{M}$ $(p<0.0001)$ (Figure 2A), while $48 \mathrm{~h}$ exposure resulted in a more significant reduction in viability at these concentrations $(p<0.0001)$ compared to vehicle alone (Figure 2B).

BITC treatment for $24 \mathrm{~h}$ had no significant effect on liver carcinoma cells but a significant reduction of cell metabolic activity was observed in prostate carcinoma cells (Figure 2A) and increasing the exposure duration to $48 \mathrm{~h}$ in the $22 \mathrm{Rv} 1$ prostate cancer model and the HepG2 liver cancer model resulted in a significant increase in cell death (Figure 2B). There was no significant difference in viability following treatment of HepG2 cells with $2.5 \mu \mathrm{M}$ BITC for $24 \mathrm{~h}$, while $48 \mathrm{~h}$ exposure resulted in significant reduction compared to the control (Figure 2A). Treatment of cells with 5, 10 and 15 $\mu \mathrm{M}$ resulted in a more significant reduction in viability $(p<0.0001)$ (Figure 2B). Twenty-four hours exposure to BITC resulted in significant reduction in viability of DU145 cells at higher concentrations only (Figure 2A) with no reduction in viability after $48 \mathrm{~h}$ treatment (Figure 2B). 22Rv1 cells were more sensitive to BITC treatment than DU145, with significant reduction in viability following $24 \mathrm{~h}$ exposure to at all concentrations. This reduction was more significant following $48 \mathrm{~h}$ exposure to $2.5,5,10$ and $15 \mu \mathrm{M}$ when compared to vehicle alone.

Exposure of HepG2 cells to increasing concentrations of long-chain ITCs PBITC and PHITC for $24 \mathrm{~h}$ showed a nonsignificant trend in cellular death but an increase of exposure to $48 \mathrm{~h}$ demonstrated a significant diminishment of cellular viability at 2.5 and $5 \mu \mathrm{M}(p<0.05)$ and $10,15 \mu \mathrm{M} ;(p<0.0001)$. PBITC treatment for $48 \mathrm{~h}$ demonstrated a significant diminishment of cellular viability at the highest concentrations $(p<0.0001)$ compared to the control (Figure 3B).

Exposure of prostate carcinoma cells for $24 \mathrm{~h}$ to longchain ITCs $(0-15 \mu \mathrm{M})$ had no significant effect on viability ( $p>0.05$ ) (Figure 3A) but increasing the exposure duration to $48 \mathrm{~h}$ resulted in an increase of cell death (Figure $3 \mathrm{~B}$ ). Exposure of DU145 cells to PHITC for $48 \mathrm{~h}$ caused significant cell death at $15 \mu \mathrm{M}(p<0.05)$, while in $22 \mathrm{Rv} 1$ cells, significant loss of viability began at the lower concentration of $2.5 \mu \mathrm{M}$. Treatment of DU145 cells with PBITC for $48 \mathrm{~h}$ resulted in significant cell death at 10 and $15 \mu \mathrm{M}(p<0.0001)$, while similarly to PHITC treatment, in 22Rv1 cells a significant decrease in viability was observed at lower concentration of $5 \mu \mathrm{M}(p<0.05)$ when compared to vehicle control.

ITC exposure of cancer cells causes a reduction of cell motility. Playing a crucial role in the progression of many diseases including cancer, cell migration is a complex process that allows these diseases to develop. For cancer treatment and the discovery of novel strategies in cancer therapy, it is vital to determine the migratory capacity of cancer cells. The wound-healing assay was utilized to 
determine the effect of natural and synthetic ITCs on the migratory capacity of liver and prostate cancer cells in vitro.

Treatment of the liver carcinoma cell line with a sub-lethal concentration $(5 \mu \mathrm{M})$ of natural ITCs resulted in a significant reduction of cell motility compared to the control $(p<0.0001$ and $p<0.05$ ) (Figures 4 and 5). Treatment of HepG2 cells with BITC for $24 \mathrm{~h}$ resulted in a greater than 4 -fold reduction of cellular migration compared to the control $(p<0.0001)$ (Figure 5). The extent of migration inhibition induced by AITC and PEITC was less, although still significant, with a motility inhibition of just over 2.8-fold reduction compared to that of the control (Figures 3 and 5). Long-chain PBITC treatment $(5 \mu \mathrm{M})$ reduced cell motility significantly $(p<0.05)$. No significant effect was observed when HepG2 cells were exposed to the same concentration $(5 \mu \mathrm{M})$ of PHITC (Figure 6).

Treatment $(5 \mu \mathrm{M})$ of androgen-independent DU145 cells with natural ITCs showed no significant reduction of migration when compared to the control, whereas BITC, AITC (Figure 5) and PBITC (Figure 6) reduced the motility of the androgen-dependent prostate cancer model (22Rv1) $(p<0.05)$ with a greater than twofold reduction compared to the control. Overall, the long-chain ITC PHITC, did not demonstrate an inhibitory effect on cellular migration in either prostate cancer cell line (Figure 6).

Colony-forming ability of ITC-treated cells is reduced in both liver and prostate cancer cells in vitro. The colonyforming assay is an in vitro cell survival assay that examines the ability of one single cell to develop into a colony of cells and undergo unrestrained division, which is a hallmark of carcinoma cells. A colony of cells is defined as 50 or more cells (21).

PEITC treatment $(2.5-10 \mu \mathrm{M})$ of DU145 cells resulted in significant reduction in colony formation at the highest concentrations $5 \mu \mathrm{M}$ and $10 \mu \mathrm{M}$, while it non-significantly reduced colony formation in 22Rv1 cells (Figure 7). Exposure of all three cell lines to increasing concentrations of AITC had no significant effect on colony-forming capability. Exposure of HepG 2 cells to increasing concentrations of BITC significantly reduced colony formation $(2.5 \mu \mathrm{M}: p<0.05 ; 5$ and $10 \mu \mathrm{M}$ : $p<0.0001)$ when compared to the control. Exposure to BITC resulted in significant reduction in DU145 colony formation at 5 and $10 \mu \mathrm{M}$. The androgen-dependent prostate cell line $22 \mathrm{Rv} 1$ was more responsive to BITC treatment and significant reduction in colony formation occurred at the lower concentration of $2.5 \mu \mathrm{M}$ in addition to 5 and $10 \mu \mathrm{M}$ (Figure 8).

Both synthetic long-chain ITCs reduced colony-forming capability to varying degrees in all three lines investigated. PBITC significantly reduced colony formation in a dosedependent manner in HepG2 cells $(2.5 \mu \mathrm{M}: p<0.05)$ and $(5$ and $10 \mu \mathrm{M}: p<0.0001$ ) [Figure 9A (i) and B (i)]. In DU145 cells, PBITC significantly reduced colony formation at all
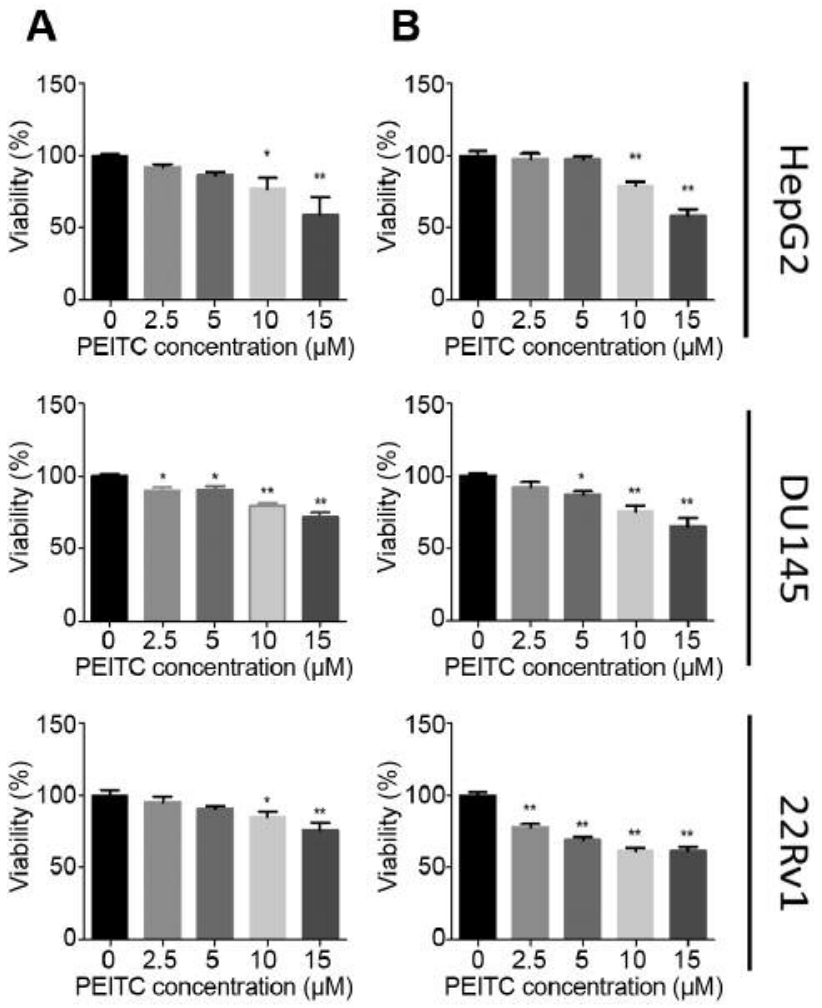

Figure 1. Phenylethyl isothiocyanate (PEITC) treatment of carcinoma cells resulted in a reduction of cellular viability in vitro. Increasing ITC concentrations (2.5-15 $\mu \mathrm{M})$ were utilized to assess the effects on viability of HepG2 liver carcinoma, and DU145 and 22Rv1 prostate carcinoma cells after $24 h(A)$ and $48 h(B)$ exposure. Results are presented as the mean $\pm S E M$. Significantly different from the untreated control at: $* p<0.05$ and $* * p<0.0001$.

concentrations [Figure 9A (ii) and B (i)]. In 22Rv1 cells, PBITC while reducing colony formation significantly at all concentration [Figure 9A (iii) and B (i)] was less effective than against DU145 cells. PHITC significantly reduced colony formation by HepG2 cells in a dose-dependent manner [Figure 9A (i) and B (ii)). It had similar action on DU145 cells ( $5 \mu \mathrm{M}: p<0.05 ; 10 \mu \mathrm{M}: p<0.0001$ ) (Figure $9 \mathrm{~B}$ (i) and (ii)] and was not as effective against $22 \mathrm{Rv} 1$ cells, with only the highest concentration of PHITC reducing colony numbers significantly $(10 \mu \mathrm{M}: p<0.05)$ [Figure 9A (iii) and B (ii)].

ITC treatment of both liver and prostate cancer cells reduced cell invasion in vitro. These studies were utilized to demonstrate the ability of ITC treatment for the prevention of cancer cell migration and invasion through an artificial extracellular matrix. For a cancer cell to invade, they must first enzymatically degrade the ECM of the new location and then become established there (22). 
A
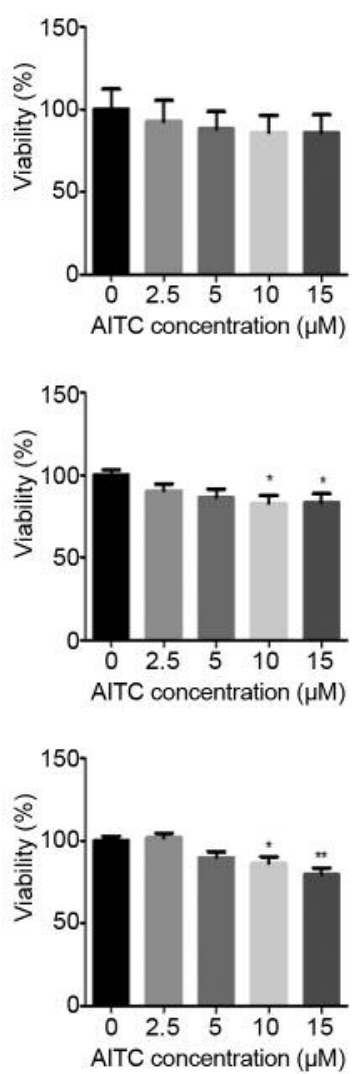
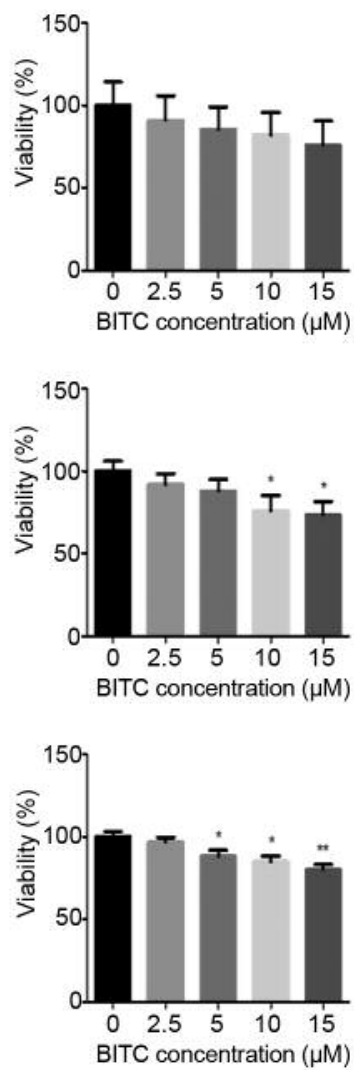

B
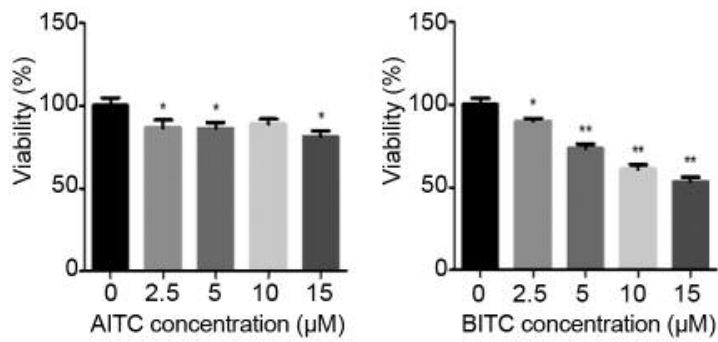

몽
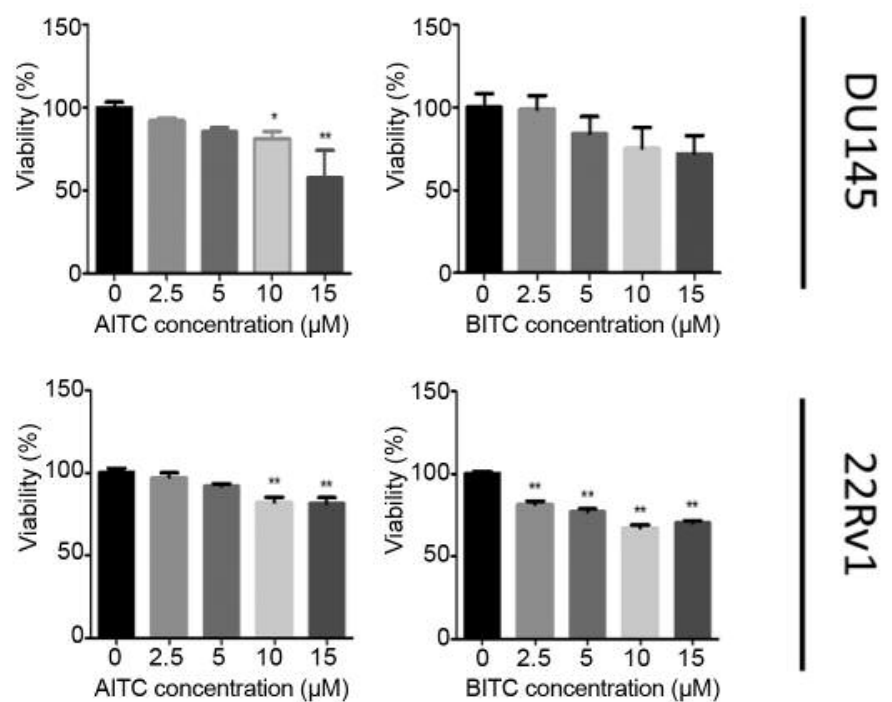

Figure 2. Natural isothiocyanates (AITC) and benzyl isothiocyanate (BITC) treatment of carcinoma cells results in reduction of cellular viability in vitro. Increasing ITC concentrations (2.5-15 $\mu \mathrm{M})$ were utilized to assess the effects on viability of various cancer cell models (HepG2, DU145 and $22 R v 1)$ after $24(A)$ and $48(B) h$ exposure. Results are represented as mean \pm S.E.M. Significantly different from the untreated control at: $* p<0.05$ and $* * p<0.0001$.

Long-chain ITC (PBITC and PHITC) treatment $(5 \mu \mathrm{M})$ of HepG2 carcinoma resulted in a significant reduction $(p<0.0001)$ of invasion through the ECM when compared to vehicle alone (Figure 10). Under the same conditions, natural ITCs did not reduce liver carcinoma cellular invasion to the same degree $(p>0.05)$.

Although a reduction was observed, the difference was not significant $(p>0.05)$ after $72 \mathrm{~h}$ treatment with natural ITC (AITC, BITC, PEITC) of the androgen-dependent prostate carcinoma cell line 22Rv1. Conversely, natural ITC treatment of DU145 prostate carcinoma cells caused a greater than $40 \%$ reduction compared to the control (vehicle alone), with AITC being the least effective (13.10\%) at suppressing invasion (Figure 11).

Synthetic ITC exposure of both prostate carcinoma models (DU145 and 22Rv1) did not inhibit the invasive capacity of these cells $(p>0.05)$ (data not shown).
ITC treatment of liver and prostate carcinoma cells resulted in apoptosis in a dose-dependent manner. In order to ascertain whether the dietary and synthetic ITCs caused cell death via apoptosis or necrosis, all cell lines were incubated for $48 \mathrm{~h}$ with increasing concentrations of each ITC (2.5-15 $\mu \mathrm{M})$ before staining with DAPI. Treatment of both liver and prostate cancer cell lines, in vitro, with increasing concentrations of ITCs induced apoptosis, which is characterized by nuclear condensation, cell shrinkage and apoptotic body formation, to name a few. All ITCs analysed had the capacity to induce apoptosis in each cell model utilized in this study (Figure 12).

The apoptotic ratio was established for all treatments and these results were then analysed. In HepG2 cells, AITC was the least effective at inducing apoptosis $(p>0.05)$. BITC and PEITC induced apoptosis in a dose-dependent manner, with the extent at $15 \mu \mathrm{M}$ being significant (BITC: $p<0.0001$ and 
A
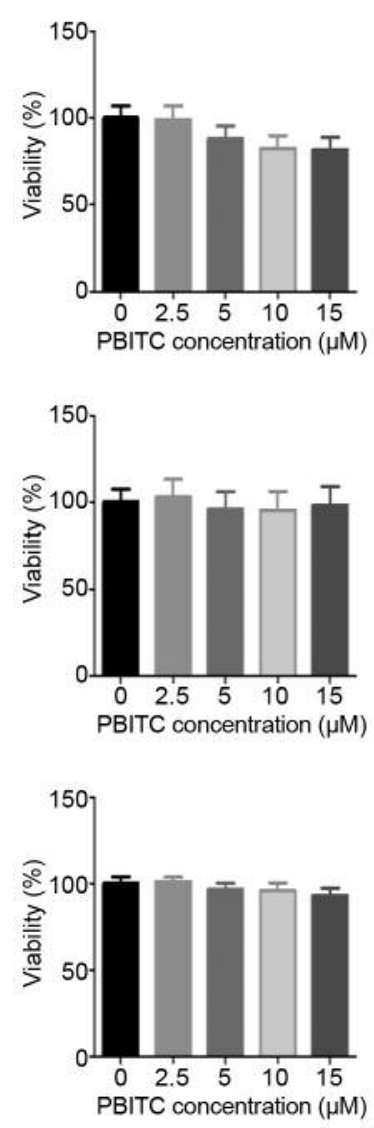
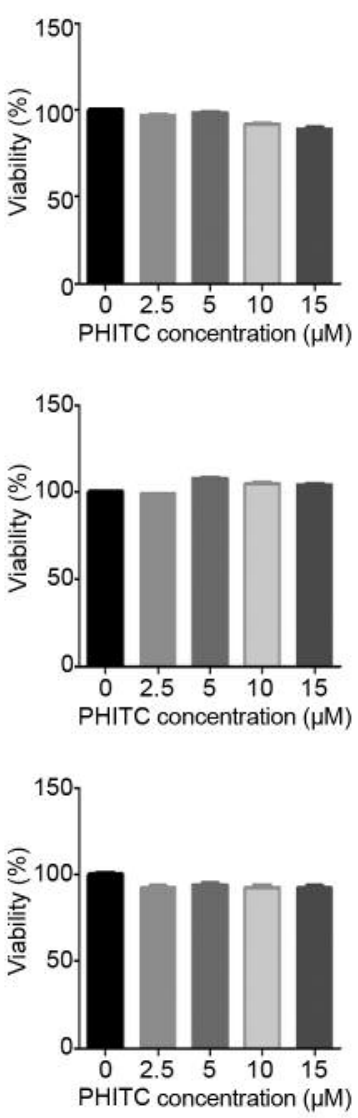

B
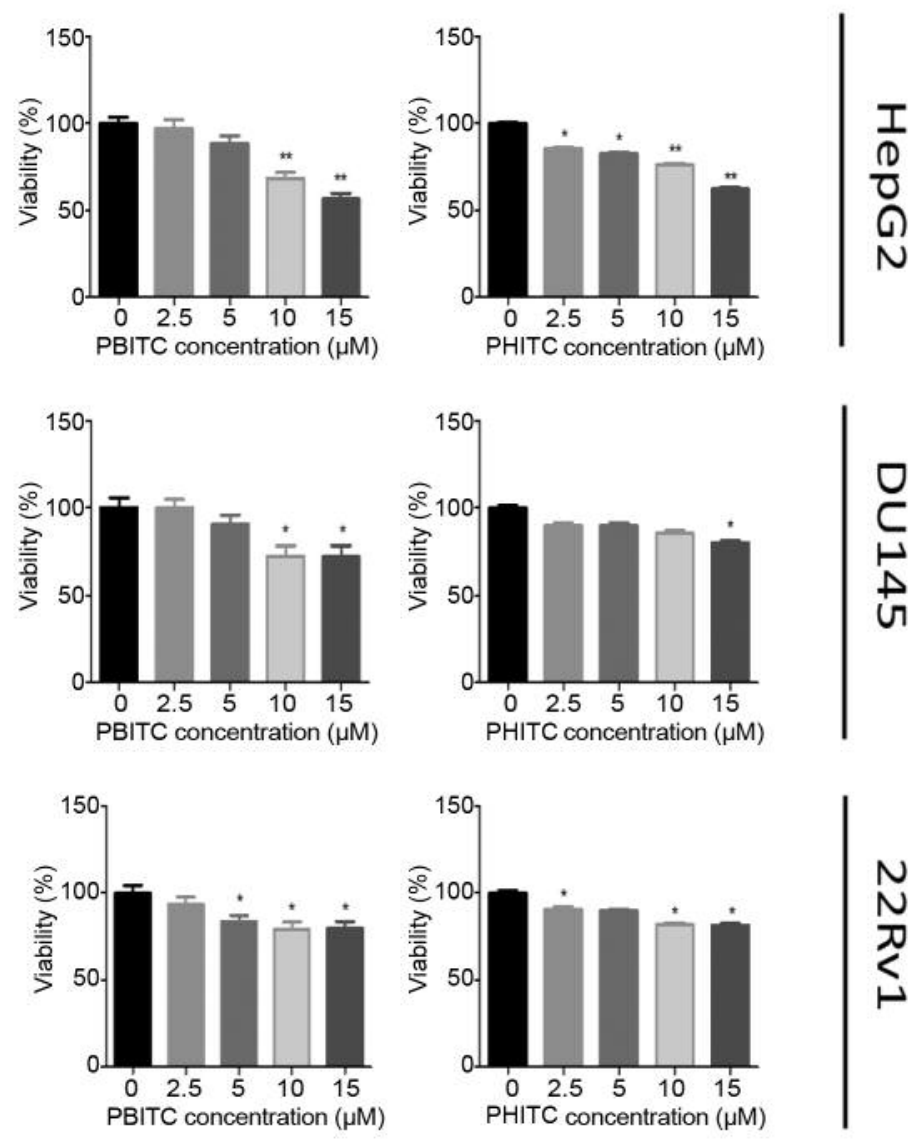

Figure 3. Treatment of carcinoma cells with synthetic phenylbutyl isothiocyanate (PBITC) and phenylhexyl isothiocyanate (PHITC) resulted in a reduction of cellular viability in vitro. Increasing ITC concentrations (2.5-15 $\mu \mathrm{M})$ were utilized to assess the effects on viability of HepG2 liver carcinoma, and DU145 and 22Rv1 prostate carcinoma cells after $24 \mathrm{~h}(\mathrm{~A})$ and $48 \mathrm{~h}(\mathrm{~B})$ exposure. Results are presented as the mean \pm SEM. Significantly different from the untreated control at: $* p<0.05$ and $* * p<0.0001$.

PEITC: $p<0.05)$. Apoptosis of DU145 cells was also induced in a dose-dependent manner by BITC and PEITC, with 15 $\mu \mathrm{M}$ significantly initiating apoptosis $(p<0.0001)$. AITC, while inducing apoptosis, did so non-significantly. There was a dose-dependent increase in apoptosis due to all natural ITCs in $22 \mathrm{Rv} 1$ cells. AITC significantly induced apoptosis at the highest concentration $15 \mu \mathrm{M}(p<0.05)$. BITC induced apoptosis significantly at $10 \mu \mathrm{M}(p<0.05)$ and $15 \mu \mathrm{M}$ $(p<0.0001)$, and PEITC at $15 \mu \mathrm{M}(p<0.0001)$. A significant initiation of apoptosis was observed at the greater concentrations of ITCs $(10$ and $15 \mu \mathrm{M})$ during the treatment of HepG2, DU145 and 22Rv1 cells.

The synthetic ITCs (PBITC and PHITC) induced apoptosis in a dose-dependent manner in all cell lines analysed. In HepG2 and DU145 cells, significance $(p<0.0001)$ was observed at the higher concentrations of 10 and $15 \mu \mathrm{M}$ PBITC. In 22Rv1 cells, significance $(p<0.0001)$ was noted at the highest concentration $(15 \mu \mathrm{M})$. PHITC also induced apoptosis in a dose-dependent fashion, with significance occurring at the highest concentration $(15 \mu \mathrm{M}$; $p<0.0001)$ for all three cell lines.

Treatment of liver and prostate cancer cell lines with natural ITCS resulted in an increase of ROS in vitro. The generation of ROS is a common biochemical alteration that occurs within transformed cells. In cancer cells, it is assumed that the generation of ROS is implicated in cell-cycle arrest and apoptosis induction (23).

With an increase of concentration natural ITCs $(5-15 \mu \mathrm{M})$, there was a resulting increase in the detection of ROS after treatment (Figure 13). For treatment of all cell lines with AITC, there was a non-significant trend towards ROS 
A (i)
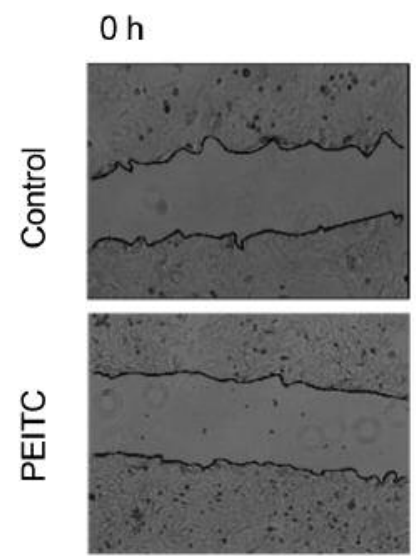

B (i)
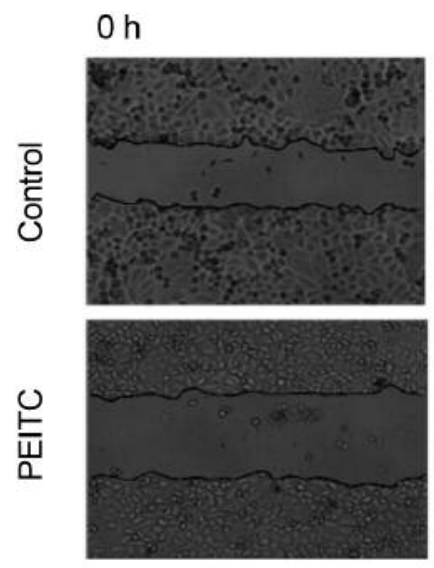

C (i)
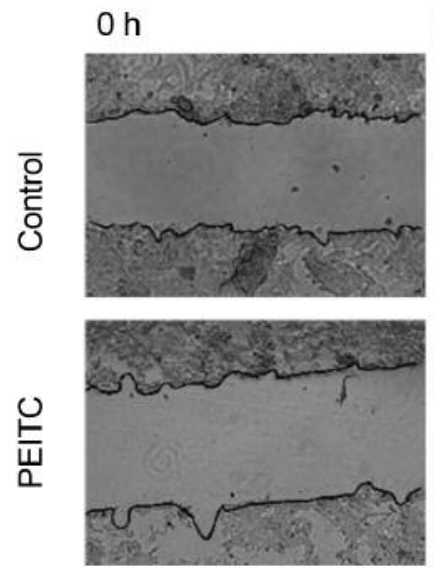

$24 \mathrm{~h}$
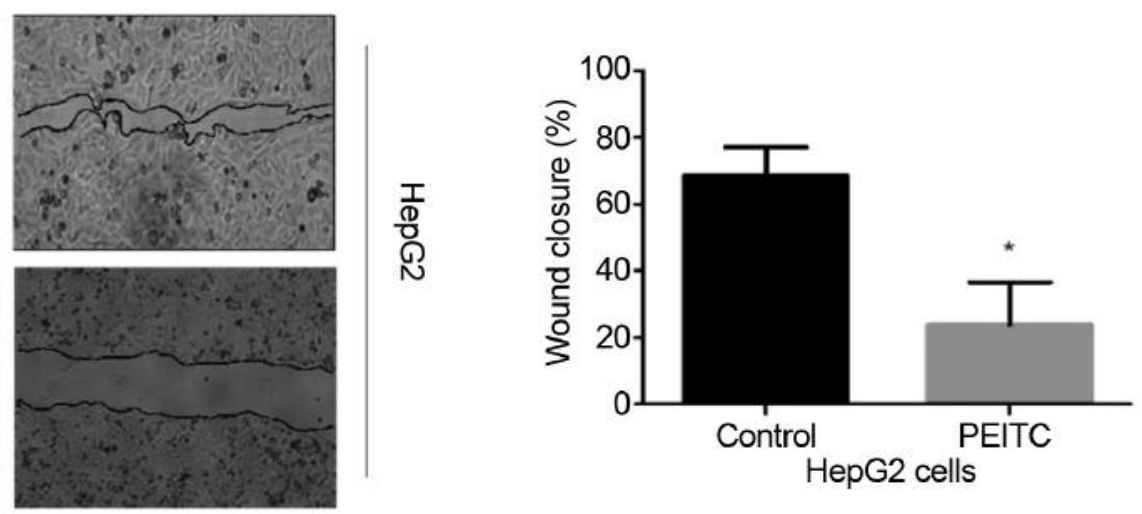

$24 \mathrm{~h}$

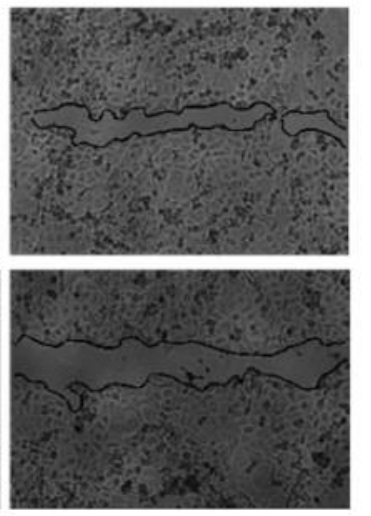

$24 \mathrm{~h}$
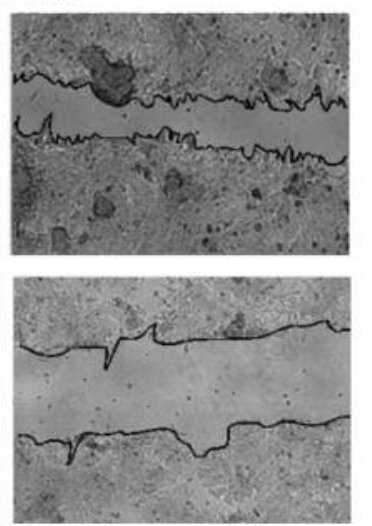

(ii)

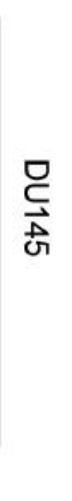

(ii)

(ii)
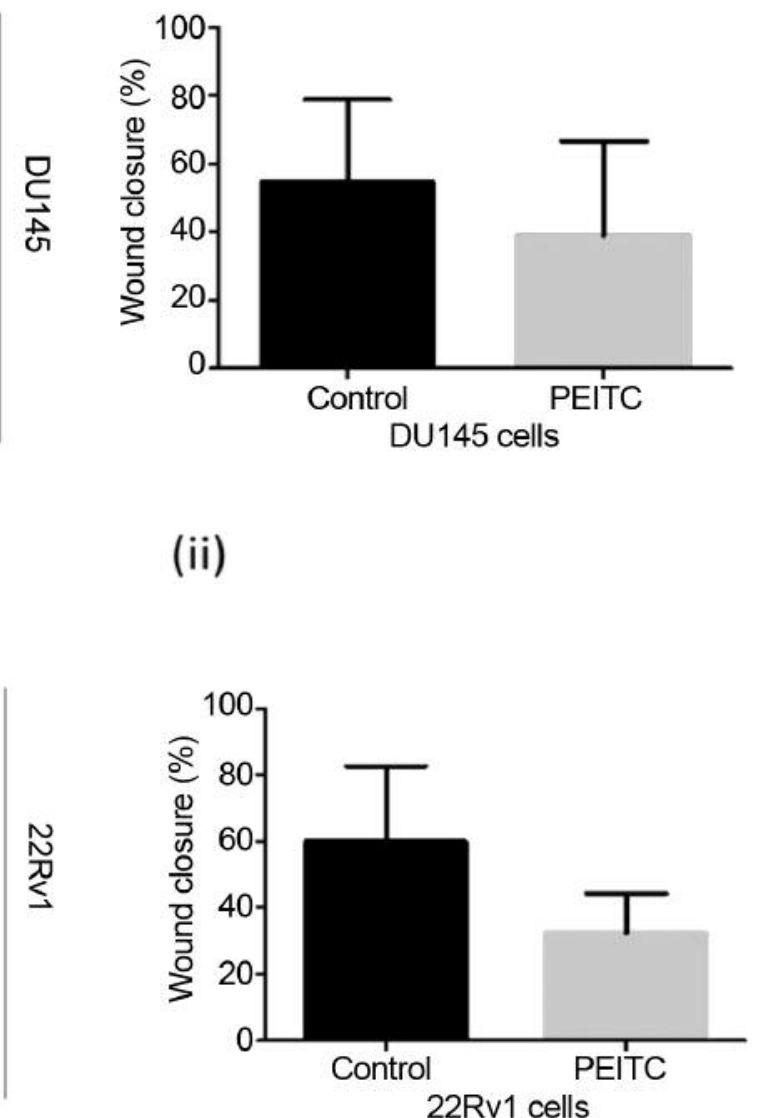

Figure 4. Phenylethyl-isothiocyanate (PEITC) affected the wound closure of HepG2. (A), DU145 (B) and 22Rv1 (C) carcinoma cells in vitro. Cells were maintained in 6-well plates for $24 \mathrm{~h}$ and were ( $i)$ wounded with a scratch, photographed and then incubated with PEITC (5 $\mu M)$ for 24 h. The relative wound closures were then photographed after 24 h. (ii) Percentage wound closure after HepG2 (A), DU145 (B) and 22Rv1 (C) cells were exposed to PEITC $(5 \mu \mathrm{M})$ or vehicle alone (Control). Cells were treated for $24 \mathrm{~h}$ at $37^{\circ} \mathrm{C}\left(5 \% \mathrm{CO}_{2}\right)$. Results were obtained from three independent experiments and are presented as the mean \pm SEM. *Significantly different from the untreated control at $p<0.05$. 


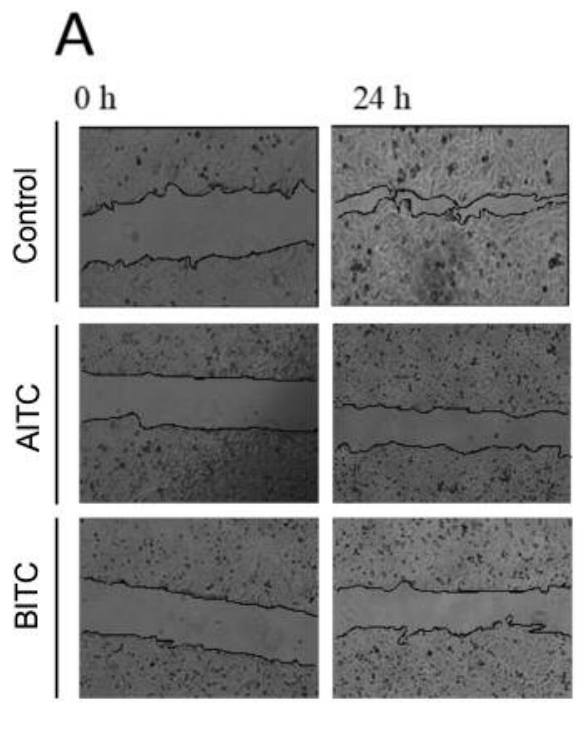

HepG2
$0 \mathrm{~h}$
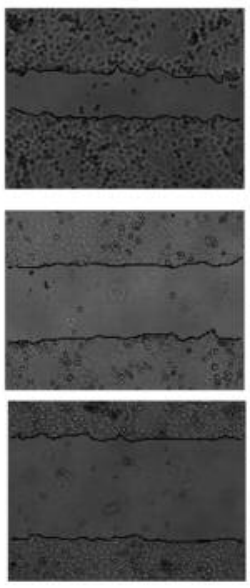

.

DU145
$24 \mathrm{~h}$
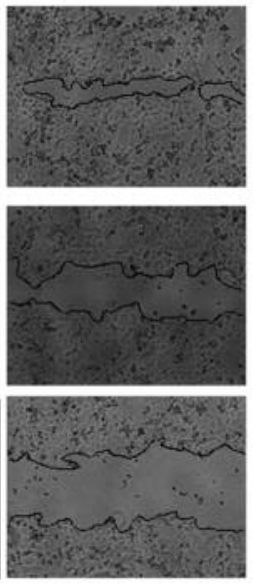

$0 \mathrm{~h} \quad 24 \mathrm{~h}$
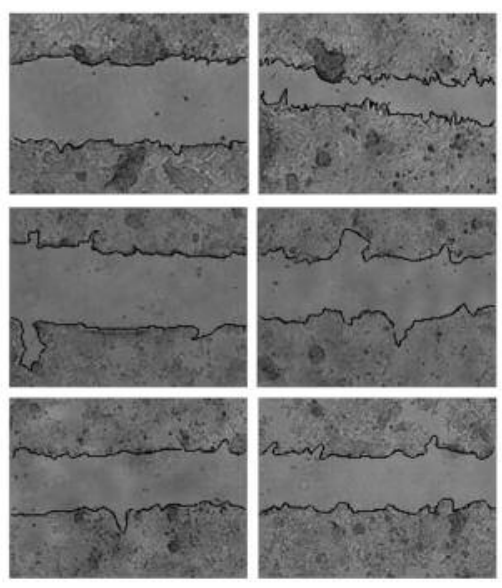

22Rv1

\section{B}

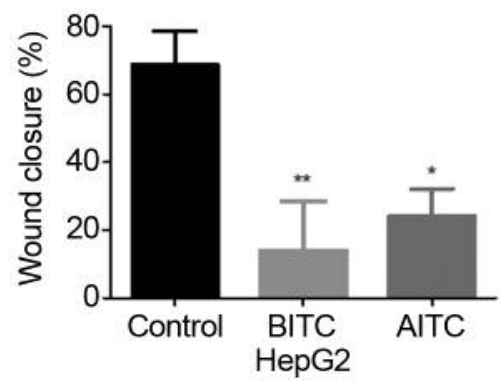

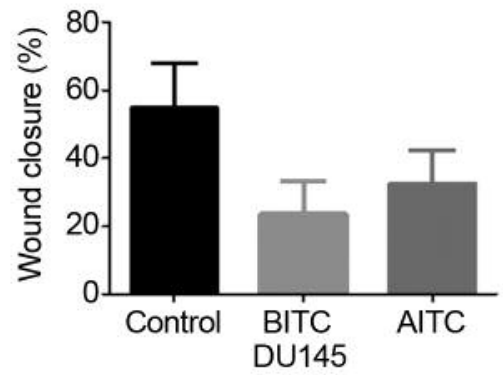

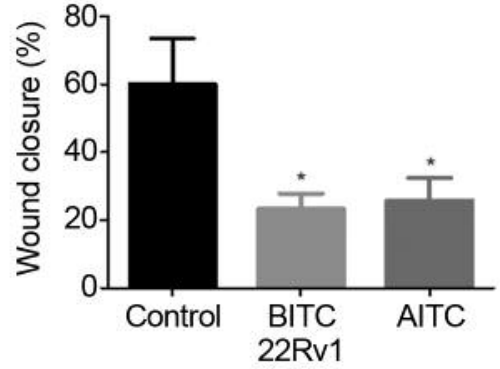

Figure 5. Natural isothiocyanate treatment affects the wound closure of HepG2, DU145 and 22Rv1 carcinoma cells in vitro. Cells were maintained in 6-well plates for $24 \mathrm{~h}$ and were wounded with a scratch, photographed and then incubated with either allyl isothiocyanate (AITC) or benzyl isothiocyanate (BITC) $(5 \mu \mathrm{M})$ for $24 \mathrm{~h}$. A: The relative wound closures were photographed at $24 \mathrm{~h}$. B: Percentage wound closure of natural ITCtreated carcinoma cells. Results are represented as mean \pm S.E.M., where significantly different from the untreated control at: $* p<0.05$ and $* * p<0.0001$.

generation $(p>0.05)$. The increase was significant at $5 \mu \mathrm{M}$ for PEITC in HepG2 cells and 22Rv1 cells $(p<0.05)$, yet while an increase was also observed in ROS in DU145 cells, the increase was not significant. BITC did not significantly increase ROS generation in HepG2 or 22Rv1 cells but did lead to an increase in DU145 cells $(p>0.05)$. At the greatest ITC concentration $(15 \mu \mathrm{M})$, a lethal threshold was hit where the viability of the exposed cells was compromised, and increased levels of ROS were not detected.

\section{Discussion}

ITCs have attracted ample interest over the years for their potential anticancer properties against many forms of cancer, including human leukemia $(24,25)$ and melanoma (26), to name only two. As part of an investigation on the anticancer potential of both natural and synthetic ITCs, this study demonstrates their chemopreventative capacity in vitro. Herein, the effects of natural ITCs (AITC, BITC, PEITC) and two long-chain synthetic ITCs (PBITC and PHITC) on the viability, colony-forming ability, migratory and invasive capacity, and apoptosis induction in HepG2 liver carcinoma cells, and DU145 and 22Rv1 prostate carcinoma cells were investigated. This study demonstrated that ITCs have the ability to act as anticancer agents in various ways through prevention of many hallmarks of cancer, including cell survival, migratory capacity, colony formation and invasion in vitro. 

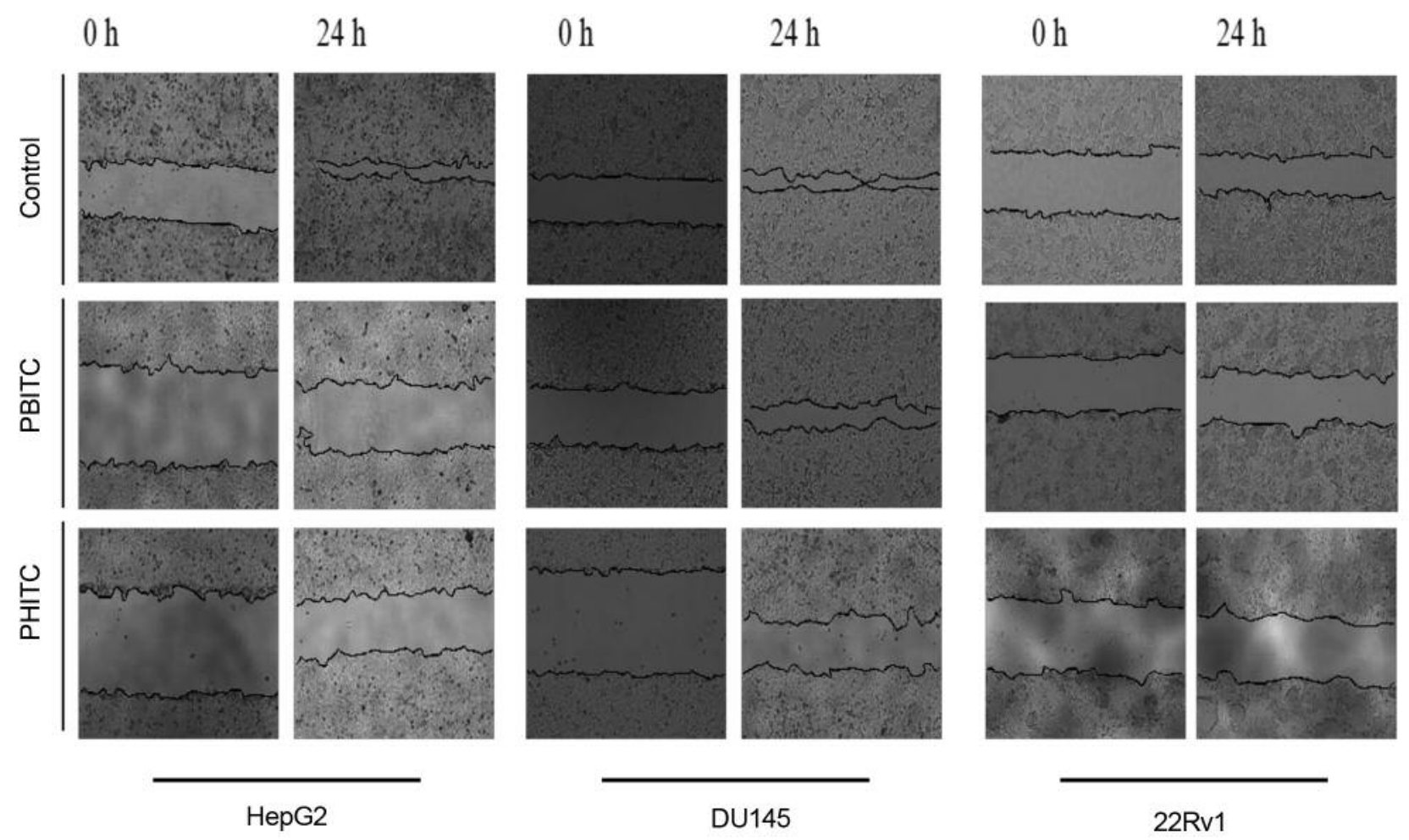

HepG2

DU145

22Rv1
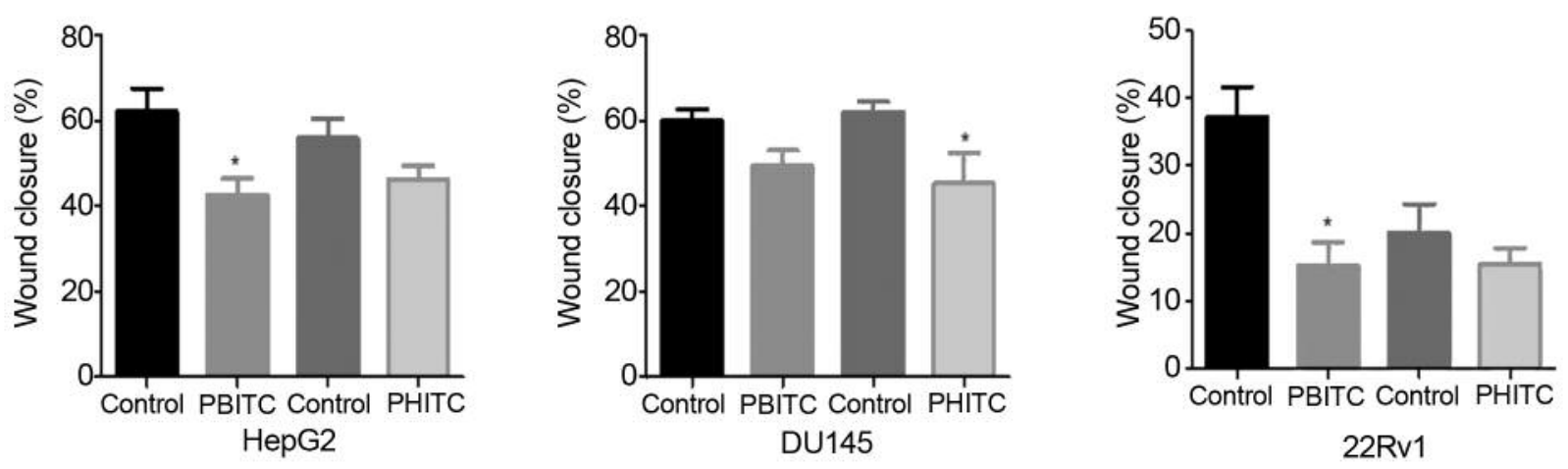

Figure 6. Synthetic isothiocyanate treatment affects the wound closure of HepG2, DU145 and 22Rv1 carcinoma cells in vitro. Cells were maintained in 6-well plates for $24 \mathrm{~h}$ and were wounded with a scratch, photographed and then incubated with either phenylbutyl isothiocyanate (PBITC) or phenylhexyl isothiocyanate (PHITC) $(5 \mu \mathrm{M})$ for $24 \mathrm{~h}$. A: The relative wound closures were photographed at $24 \mathrm{~h}$. B: Percentage wound closure of natural ITC-treated carcinoma cells. Results are represented as mean \pm S.E.M. *Significantly different from the untreated control at $p<0.05$.

Our results demonstrated that all ITCs, while attenuating specific cancer 'hallmarks', also led to apoptosis induction. Exposure to ITCs potently reduced the survival of all cell tines in a dose-dependent manner. The viability of all three cell lines was notably reduced by each ITC in a concentration and time-dependent manner. This study showed that increasing the exposure duration resulted in a more significant cytotoxic effect on all cell lines examined. Dose-dependent cell survival reduction has been observed in ITC-exposed HeLa cells, with particular recognition that the carbon chain length of the ITC affects its chemopreventative effectiveness (27).

The in vitro cytotoxicity results indicated that PEITC, the longest natural ITC in this investigation, showed higher cytotoxic activity against the androgen-independent prostate cell line DU145 compared to the HepG2 and 22Rv1 cell models. The viability of each cell line was significantly reduced after exposure to increasing concentrations of PEITC. Previous study to date, demonstrating the influence 

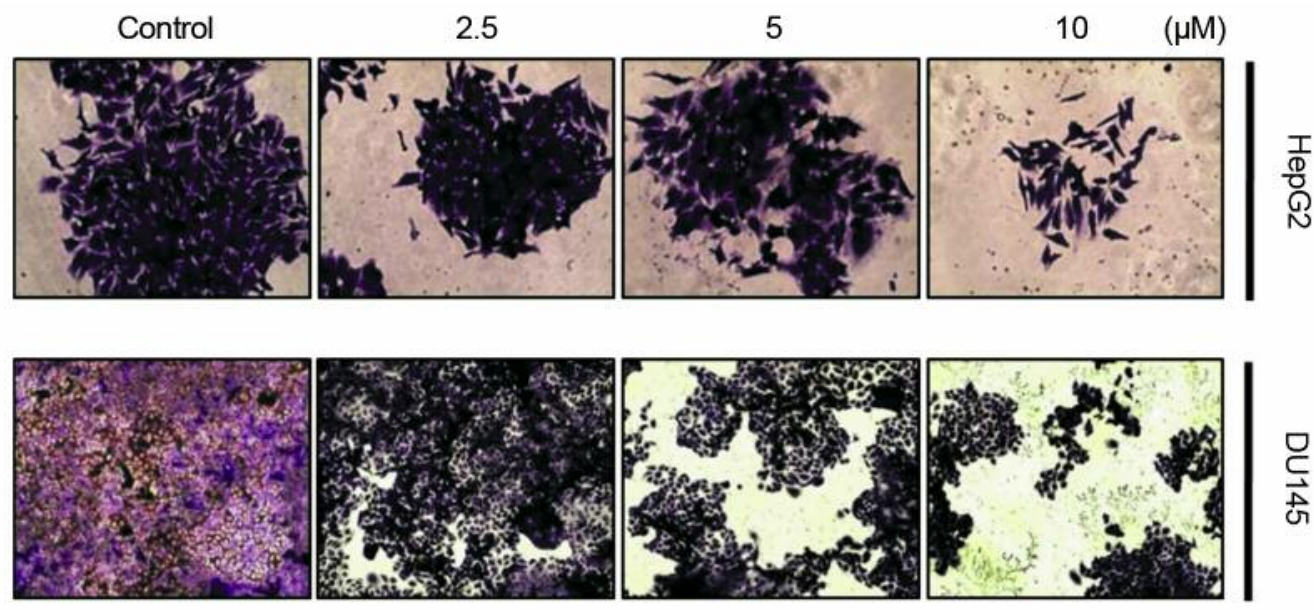

\section{$\frac{\text { C }}{\text { 妾 }}$}
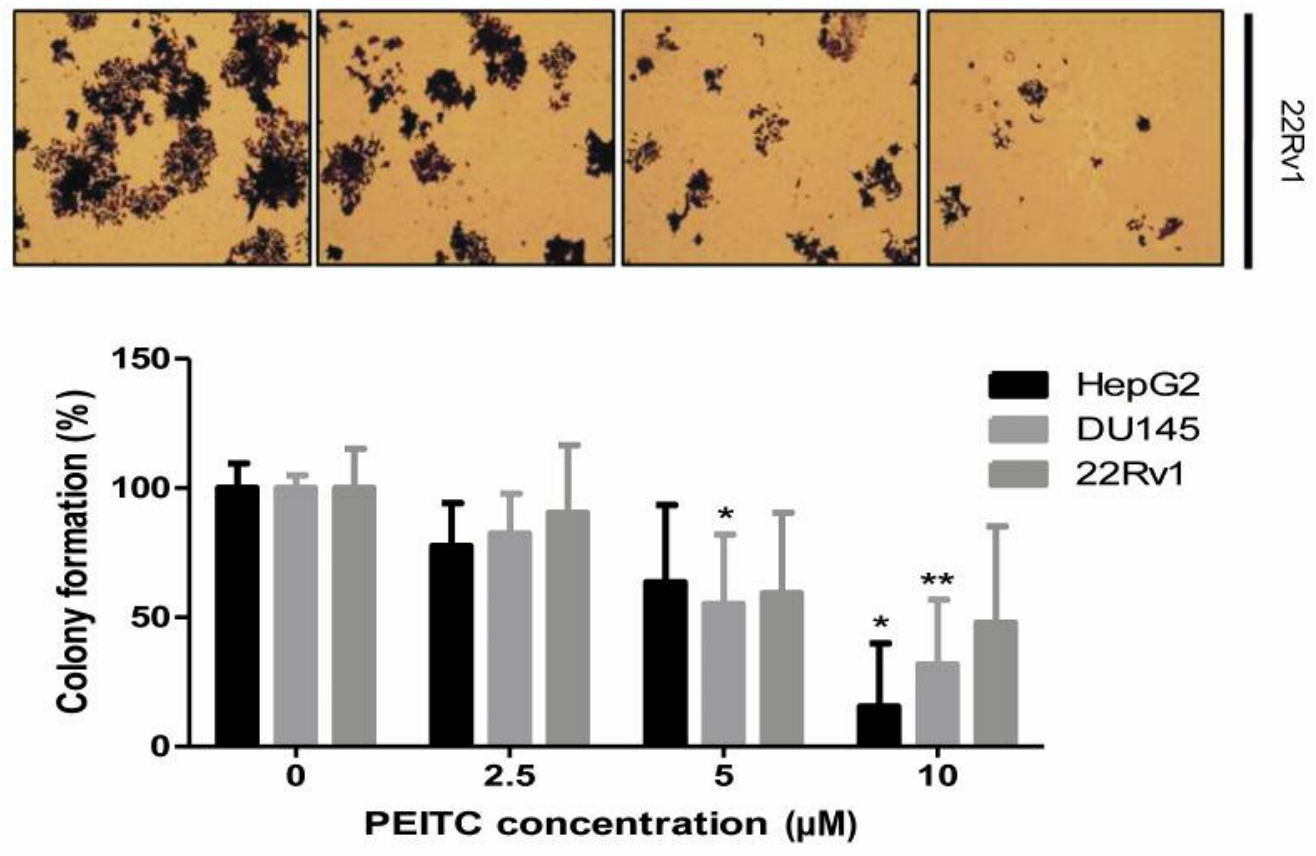

Figure 7. Phenylethyl isothiocyanate (PEITC) treatment of liver and prostate cancer cells resulted in a reduction of colony formation. HepG2, DU145 and 22Rv1 cells were exposed to increasing concentrations of PEITC $(0,2.5,5$ and $10 \mu M)$ for 24 h. Crystal violet staining highlighted the reduction of colony formation with an increase of PEITC concentration. Results are presented as the mean \pm SEM from three independent experiments. Significantly different from the untreated control at: $* p<0.05$ and $* * p<0.0001$.

of carbon chain length on tumorigenesis inhibition, showed that the potential for inhibition increases with carbon chain length, up to eight carbons, as they possess a longer half-life in cells as a result of reduced conjugation with glutathione and excretion from the cell (16). PEITC has also been shown to be a more potent inhibitor of lung tumorigenesis in vivo than the effects observed for BITC (28).

A greater reduction of cell viability was observed where HepG2 cells were exposed to BITC, PEITC, PBITC or PHITC (Figure 2) for $24 \mathrm{~h}$. Xiao et al. discovered that AITC causes significant inhibition of prostate cell proliferation in a concentration-dependent manner via cell-cycle arrest and apoptosis induction. It is believed that AITC and other structurally related ITCs could be beneficial in preventing or slowing down human prostate cancer. Isothiocyanatemediated inhibition of cell growth may be prostate cellspecific (29).

Using the wound-healing assay for cell migration, shortchain ITCs were shown to significantly suppress the migration of HepG2 cells. Investigating the effects of long- 
A $\mathrm{i}$

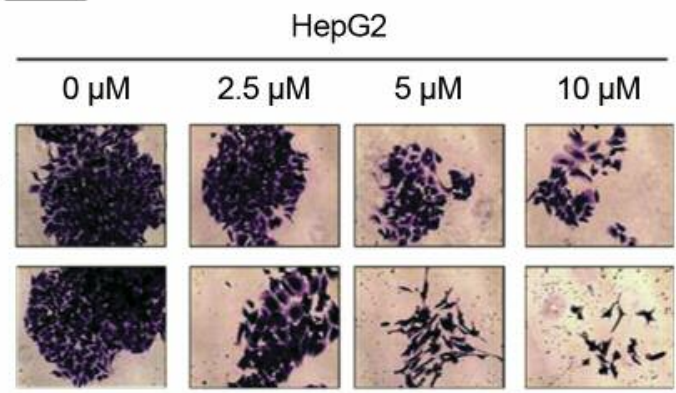

\section{ii}
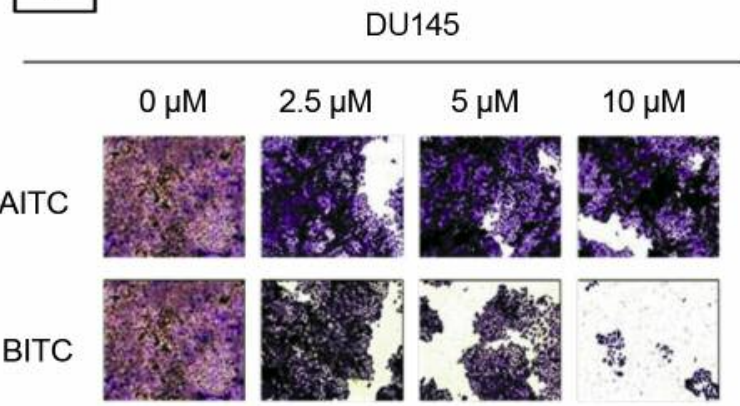

iii 22Rv1

AITC

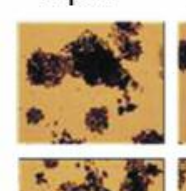

BITC

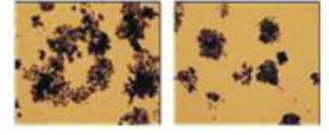

\section{$2.5 \mu \mathrm{M}$}

$5 \mu \mathrm{M}$

$10 \mu \mathrm{M}$
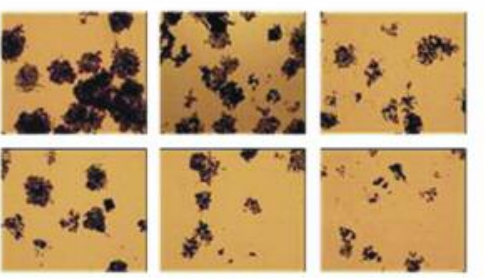

$\mathbf{B}$
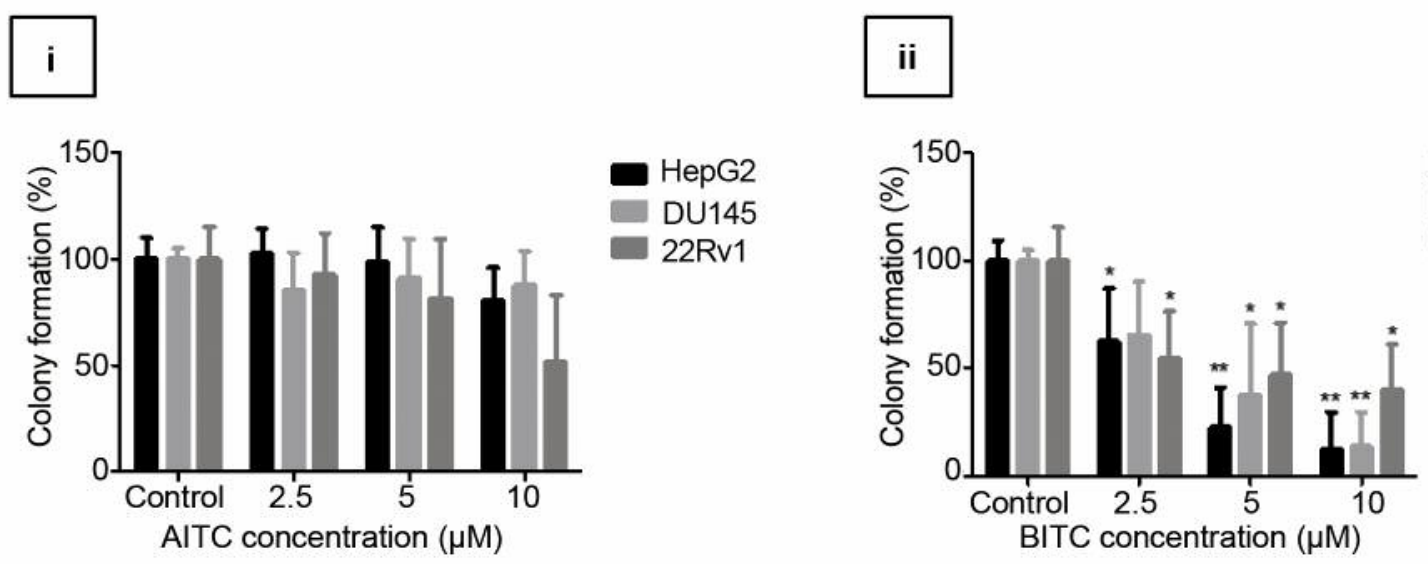

HepG2

DU145

22Rv1

Figure 8. A: Natural isothiocyanate treatment of liver and prostate cancer cells results in a reduction of colony formation. HepG2 (i), DU145 (ii) and 22Rv1 (iii) cells were exposed to increasing concentrations of allyl isothiocyanate (AITC) or benzyl isothiocyante $(B I T C)(0,2.5,5$ and $10 \mu M)$ for $24 \mathrm{~h}$. The colony formation ability of carcinoma cells was determined by staining using crystal violet (as described in the Materials and Methods section) highlighting the reduction of colony formation with an increase of ITC concentration. B: Quantification of results shown in (A). Results were obtained from three independent experiments and are represented as mean $\pm S . E . M$. Significantly different from the untreated control at: ${ }^{*} p<0.05$ and $* * p<0.0001$.

chain ITC treatment in the suppression of migration of HepG2 cells showed a significant effect using PBITC while there was no significant suppression by PHITC. Although a reduction of cellular mobility was seen in DU145 cells exposed to sub-toxic concentrations of ITC, there was no significant suppression compared to the control. In $22 \mathrm{Rv} 1$ carcinoma cells, the migration of those exposed to BITC,
AITC or PBITC was significantly reduced compared to control whereas PEITC and PHITC showed no significant suppression. These results clearly indicate that cytotoxic effects of ITCs depend on the cell line and ITC in question.

The in vitro cell survival assay, also known as the clonogenicity assay, was used to examine ITC-treated cells for their capacity to go through unrestrained division (21). 
A $\mathbf{i}$

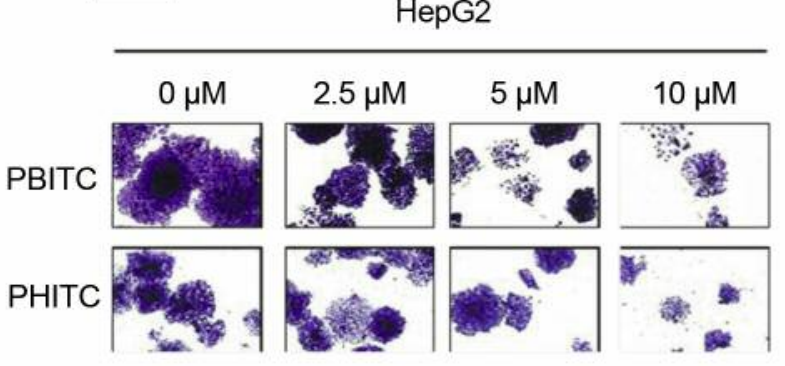

\section{ii}
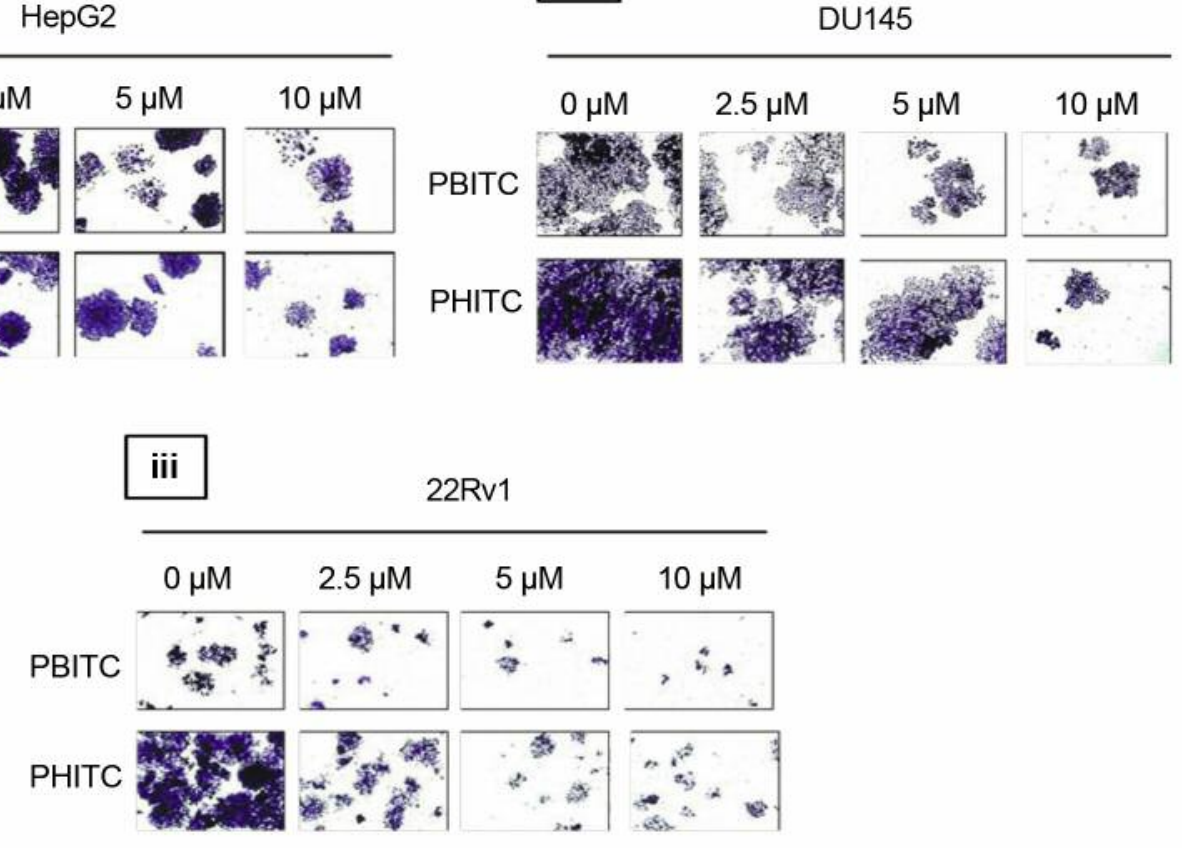

B

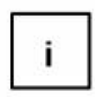

i

ii
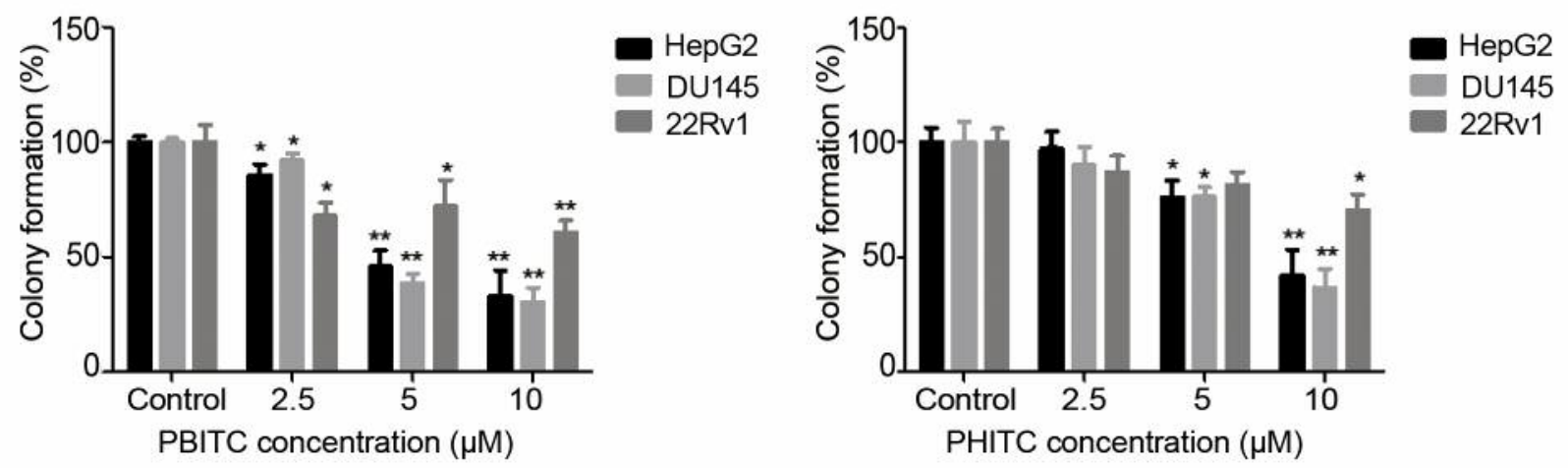

Figure 9. A: Synthetic isothiocyanate treatment of liver and prostate cancer cells results in reduction of colony formation. HepG2 (i), DU145 (ii) and 22Rv1 (iii) cells were exposed to increasing concentrations of phenylbutyl isothiocyanate (PBITC) or phenylhexyl isothiocyanate (PHITC) ( 0 , 2.5, 5 and $10 \mu \mathrm{M}$ ) for $24 \mathrm{~h}$. The colony formation ability of carcinoma cells determined by staining using crystal violet (as described in the Materials and Methods section) highlighting the reduction of colony formation with an increase of ITC concentration. B: Quantification of results shown in (A). Results were obtained from three independent experiments and are represented as mean \pm S.E.M. Significantly different from the untreated control at: $* p<0.05$ and $* * p<0.0001$.

This assay investigates the long-term proliferative capacity of cells over a period of 7 days post-ITC exposure.

As shown in the Results section, the number of viable colonies was reduced with an increase in PEITC concentration in all cell models. For each ITC, an increase of ITC concentration resulted in a proportionate decrease in the ability of each cell line to form colonies in. Exposing all three cell lines to increasing concentrations of each ITC individually demonstrated that some ITCs have a greater capacity to inhibit colony formation in one cell line more than another. PEITC at $10 \mu \mathrm{M}$ was shown to inhibit the control from forming colonies in vitro, resulting in only $15 \%$ of cells 
A $\mathrm{i}$

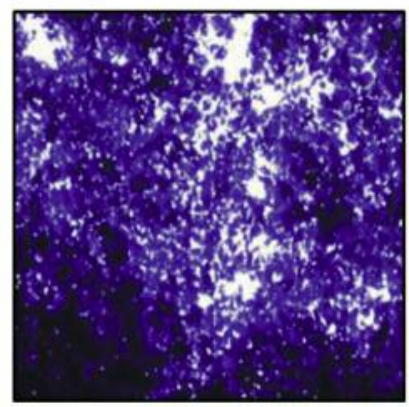

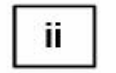

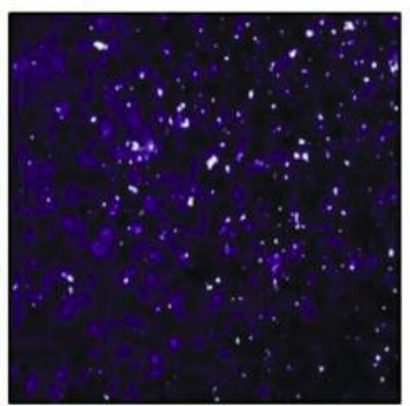

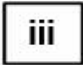

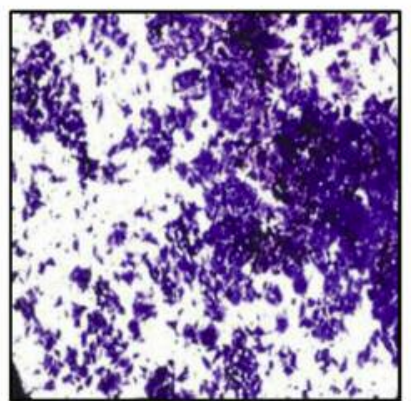

\section{iv}

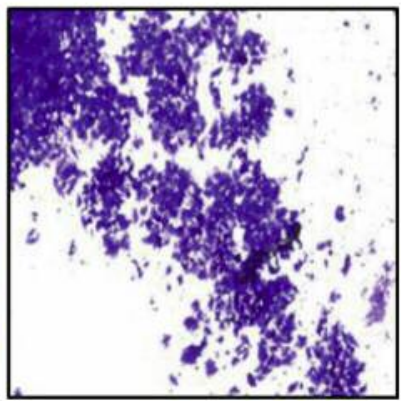

B

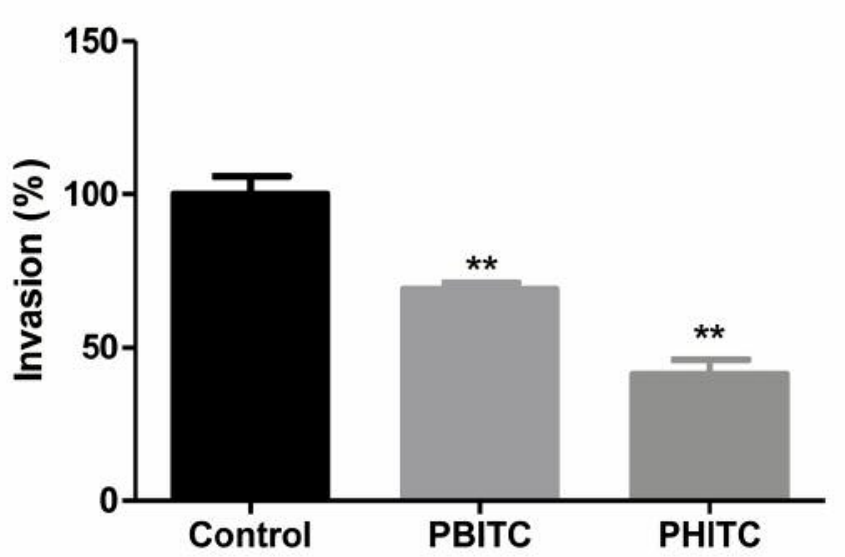

Figure 10. A: Effect of long-chain isothiocyanates on HepG2 cell invasion in vitro. Compared to the effect of vehicle alone on HepG2 cells ( $i$ and ii), phenylbutyl- isothiocyanate (PBITC) (iii) and phenylhexylisothiocyanate (PHITC) (iv) reduced invasion through the extracellular matrix (ECM). B: Percentage invasion of long-chain ITC treated HepG2 cells through the ECM compared to the control. Representative images of cells that had invaded through the ECM after an incubation period of $72 \mathrm{~h}$ are shown. Results are presented as the mean \pm SEM. **Significantly different from the untreated control at $p<0.0001$.

seeded forming colonies after ITC exposure Overall, HepG2 cell colony formation as a result of ITC treatment was more sensitive than both of the other cell lines examined. Data provided by the colony-forming assay is not indicative of cell death or survival but signifies cells that have lost the potential to independently reproduce and develop into a colony of cells in vitro. ITC-treated cells that have lost the ability to do so are unlikely to relapse in cancer, but this does not indicate that they have lost the potential to enter the cell cycle (30).

Many reports in the literature have indicated that metastatic cancer is responsible for over $80 \%$ of cancer deaths (31). Our results indicated that long-chain synthetic ITCs (PBITC and PHITC) significantly reduced the cellular invasion of HepG2 cells, while they did not in both prostate cancer cell lines (DU145/22Rv1) in vitro. This indicates that ITCs may be cell line-specific for invasion suppression.

These chemopreventative agents are also capable of inducing apoptosis, programmed cell death, in the two cancer models utilized in this study, liver (HepG2) and prostate carcinoma (22Rv1 and DU145).

The ability of PEITC to induce apoptosis in prostate carcinoma resulting in a reduction of cellular viability in vitro was demonstrated by Xiao et al. (32) in both androgenindependent (PC-3) and androgen-dependent ( $\mathrm{LNCaP}$ ) cell lines in vitro. Cells treated with vehicle alone and lower concentrations of ITC $(2.5 \mu \mathrm{M})$ maintained their plasma membrane integrity when treated for a duration of $48 \mathrm{~h}$ in vitro. Concentrations as low as $5 \mu \mathrm{M}$ have shown the potential to induce plasma membrane leakage in prostate and liver cancer. HepG2 cells demonstrated significant apoptosis induction treated with BITC and PBITC (10 and $15 \mu \mathrm{M})$. The same behavior at a greater concentration of PEITC (Figure 12) and PHITC (15 $\mu \mathrm{M})$ was observed in HepG2 cells compared to vehicle alone with evident apoptotic characteristics such as condensed nuclear material, fragmentation and apoptotic body formation identified.

In previous study, BITC was shown to cause apoptosis in various forms of human carcinoma models including breast and prostate cancer (33), while the synthetic ITC, PHITC has been shown to induce apoptosis in the $\mathrm{LNCaP}$ prostate carcinoma model (34). Each ITC investigated in this study induced apoptosis in the androgen-independent cell line, DU145. ITC concentrations as low as $5 \mu \mathrm{M}$ proved adequate to disrupt the cell membrane for the larger ITCs (BITC, 

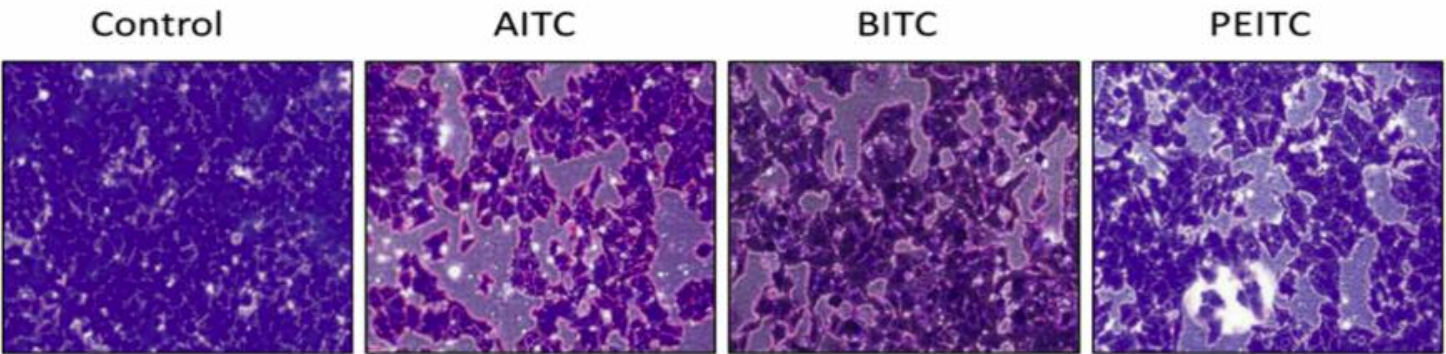

\section{甹}
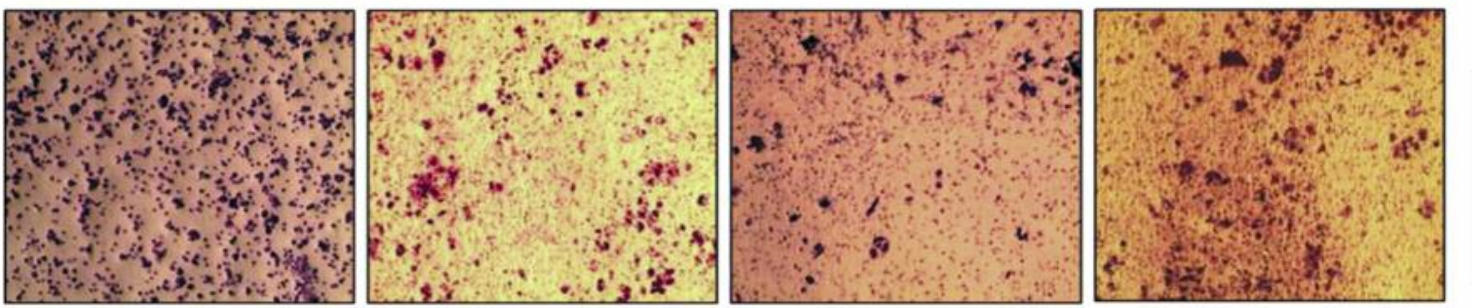

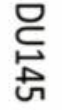
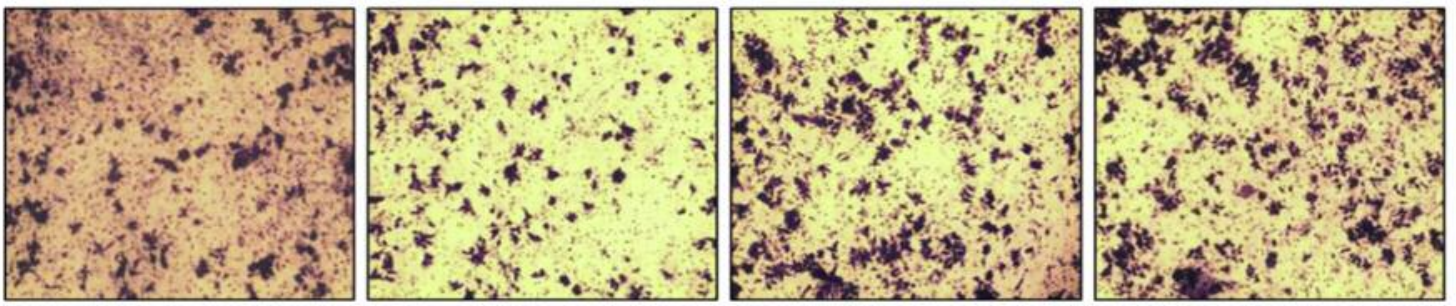

N
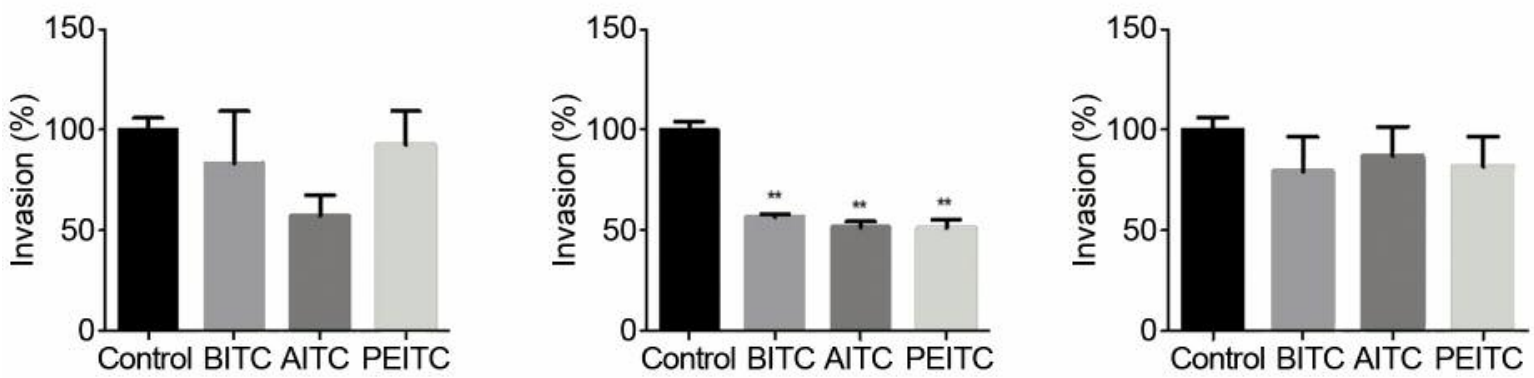

Figure 11. Natural isothiocyanates allyl isothiocyanate (AITC), benzyl isothiocyanate (BITC) and phenylethyl isothiocyanate (PEITC) treatment of carcinoma cells results in a reduced cellular invasion through the ECM. Invasive, crystal violet stained cells were photographed using a light microscope and solubilized using glacial acetic acid for graphical representation. Results are presented as mean \pm S.E.M. **Significantly different from the untreated control at $p<0.0001$.

PEITC, PBITC and PHITC), whereas the slightly higher concentration of $10 \mu \mathrm{M}$ AITC was needed to induce a similar disruption showing signs of early apoptosis such as condensation. Similarly to DU145, the androgen-dependent cell line 22Rv1 demonstrated evident signs of apoptosis when exposed to each ITC in question. For all cell lines, AITC was the least effective ITC at inducing apoptosis compared to the control with no significant effect observed on HepG2 and DU145 cells, while the highest concentration used displayed a significant effect on $22 \mathrm{Rv} 1$ cells in vitro. This suggests the apoptosis-inducing potential of ITCs can vary between cell types and seems to be largely inspired by the compounds chemical structure as was previously reported (11).

Many studies carried out to date demonstrate that ROS generation leads to programmed cell death as a result of ITC exposure (23). Treatment of human melanoma cells with BITC resulted in the increase of ROS levels in a time-dependent manner resulting in early events of programmed cell death within the cells (26). It was initially expected that increasing concentrations of ITC treatment would result in a corresponding increase of ROS generation in a time-dependent manner. Data from this study demonstrate, in some cases, that 


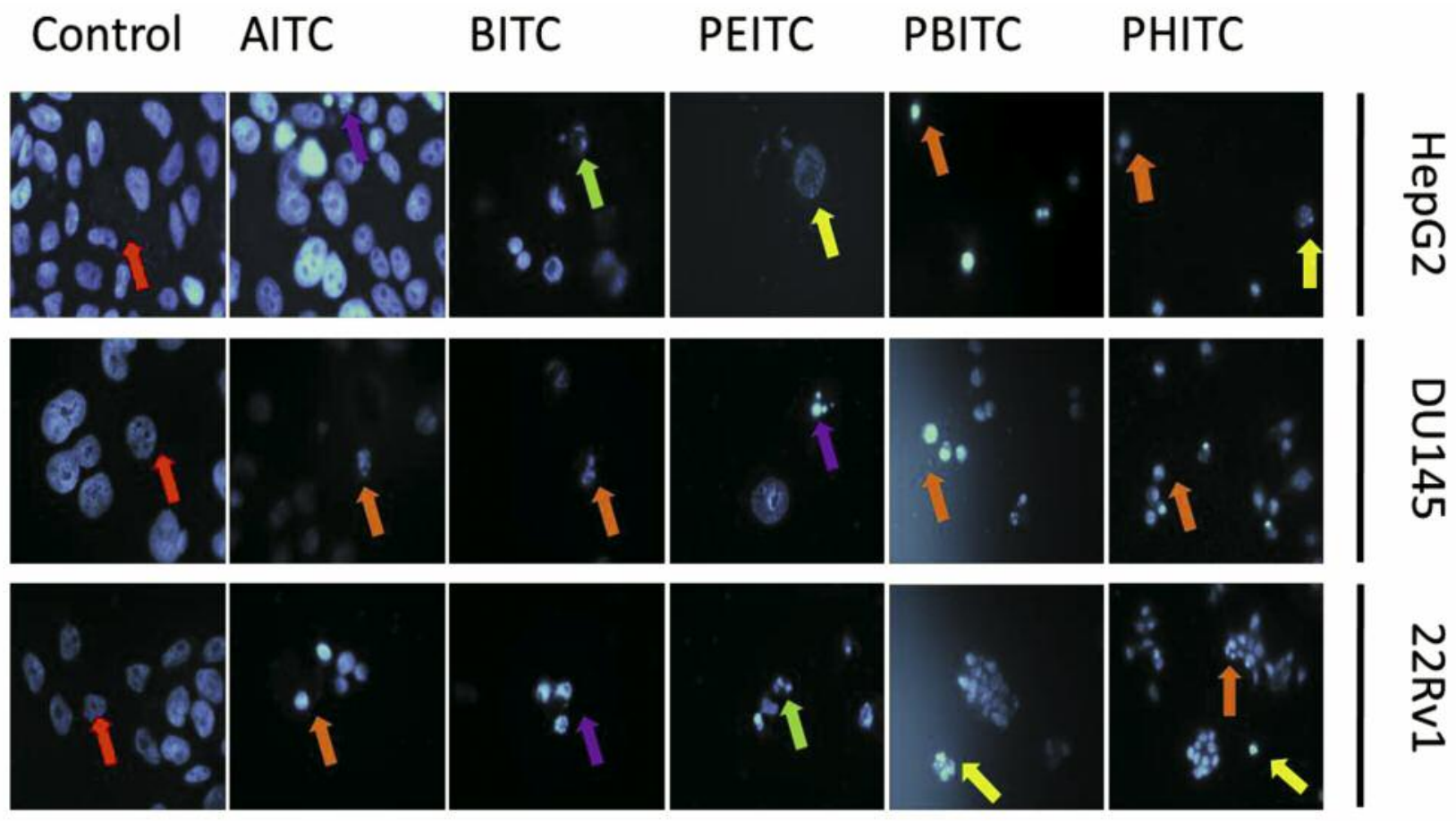

\section{Apoptosis Key:}

Normal

Late apoptosis

Condensation

Fragmentation

Apoptotic bodies
Figure 12. Isothiocyanates induced apoptosis of HepG2, DU145 and $22 R v 1$ carcinoma cells in vitro. Cells were treated with increasing concentrations $(0-15 \mu M)$ of allyl-isothiocyanate (AITC), benzylisothiocyanate (BITC), phenylethyl- isothiocyanate (PEITC), phenylbutyl-isothiocyanate (PBITC) and phenylhexyl-isothiocyanate (PHITC) for $48 \mathrm{~h}$. Cells were harvested for 4',6-diamidino-2phenylindole staining and were then examined using a fluorescent microscope for apoptotic characteristics. Results above show apoptosis induction at the greatest concentration $(15 \mu M)$ for each ITC.
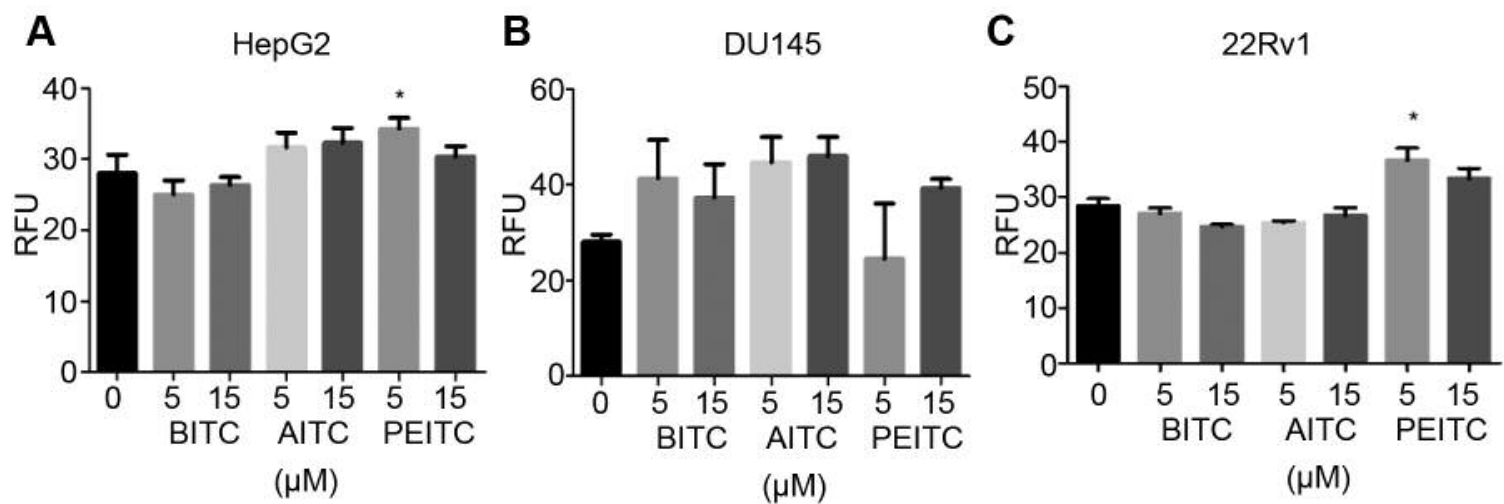

Figure 13. The effect of benzyl-isothiocyanate (BITC), allyl-isothiocyanate (AITC) and phenylethyl-isothiocyanate (PEITC) on reactive oxygen species production in HepG2 (A), DU145 (B) and 22Rv1 (C) carcinoma cells in vitro. Results are presented as the mean $\pm S E M . *$ Significantly different from the untreated control at $p<0.05$. 
at a greater ITC concentration there was a reduction of ROS detected (Figure 13). Tang et al. noted the ability of ITCs to damage the cell surface membrane causing leakage of intracellular components into the culture medium during ITC treatment (35). This may be the explanation for the reduction of ROS detected at greater ITC concentration. Literature on various carcinoma cell models has outlined the ability of BITC $(12,32)$ and other ITCs to induce ROS as a method of intracellular signaling culminating in apoptosis (36).

Apoptosis induction via ROS generation in ITC-treated carcinoma cells may possibly elucidate some of the molecular mechanisms responsible for the anticancer potential of ITCs in many forms of cancer including liver and prostate cancer in vitro. ITC treatment causes ROS production, triggering both intrinsic and extrinsic pathways of apoptosis resulting in caspase-3 activation (26).

Taken together, the results reported here indicate that ITCs have the ability to reduce cell viability, colony formation, mobility and invasion of both liver and prostate carcinoma in vitro while also inducing programmed cell death. In conclusion, data from the present study demonstrate that ITCs effectively reduce liver and prostate carcinoma (androgen-dependent and-independent) viability, migratory capacity and invasiveness while inducing these cancerous cells to undergo apoptosis. Based on these results and observations in various studies to date, it is rational to assume that ITCs may be advantageous for delaying initiation or progression of liver and prostate carcinoma.

\section{Conflicts of Interest}

The Authors declare no conflict of interest in regard to this study.

\section{Authors' Contributions}

Emily Crowley conceived and designed the experiments, collected the data, performed the analysis and wrote the paper. Neil J Rowan wrote the paper and provided research infrastructure. Don Faller edited the paper and provided research infrastructure. Anne M. Friel conceived and designed the experiments and wrote the paper.

\section{Acknowledgements}

The Authors thank Professor Lorraine O' Driscoll (Trinity College Dublin) for providing the DU145 and 22Rv1 cell lines.

\section{References}

1 Hanahan D and Weinberg RA: The hallmarks of cancer. Cell 100: 57-70, 2000. PMID: 10647931.

2 Fimognari C, Nusse M, Berti F, Iori R, Cantelli-Forti G and Hrelia P: Isothiocyanates as novel cytotoxic and cytostatic agents: Molecular pathway on human transformed and nontransformed cells. Biochem Pharmacol 68: 1133-1138, 2004. PMID: 15313410. DOI: 10.1016/j.bcp.2004.03.044
3 Bertram JS: The molecular biology of cancer. Mol Aspects Med 21: 167-223, 2000. PMID: 11173079. DOI: 10.1016/S00982997:00)00007-8

4 Cheung KL and Kong A-N: Molecular targets of dietary phenethyl isothiocyanate and sulforaphane for cancer chemoprevention. AAPSJ 12: 87-97, 2010. PMID: 20013083. DOI: $10.1208 / \mathrm{s} 12248-009-9162-8$

5 Society IC: Cancer mortality, 2019. Available from: https:// www.cancer.ie/about-us/media-centre/cancer-statistics\# sthash.fZpcvDUk.dpbs. Last accessed on March 7, 2019.

6 Deady S, McDevitt J, O'Brien K, O'Leary E and Walsh P: Cancer trends no 31: Primary liver cancer. National Cancer Registry Board Ireland, 2016. Available from: https://www. ncri.ie/sites/ncri/files/pubs/Liver\%20trendsDecember2016_0.pdf. Last accessed on March 7, 2019.

7 McGrath A: Understanding prostate cancer. Irish Cancer Society: Understanding Series, 2018. Available from: https:// www.cancer.ie/publications/cancer-types\#sthash.mPd5I6kF.dpbs. Last accessed on March 7, 2019.

8 Gupta P, Wright SE, Kim SH and Srivastava SK: Phenethyl isothiocyanate: A comprehensive review of anticancer mechanisms. Biochim Biophys Acta 1846: 405-424, 2014. PMID: 25152445. DOI: 10.1016/j.bbcan.2014.08.003

9 Hayes JD, Kelleher MO and Eggleston IM: The cancer chemopreventive actions of phytochemicals derived from glucosinolates. Eur J Nutr 47: 73-88, 2008. PMID: 18458837. DOI: $10.1007 / \mathrm{s} 00394-008-2009-8$

10 Fahey JW, Zalcmann AT and Talalay P: The chemical diversity and distribution of glucosinolates and isothiocyanates amoung plants. Phytochemistry 56: 5-51, 2001. PMID: 11198818. DOI: 10.1016/S0031-9422(00)00316-2

$11 \mathrm{Wu} \mathrm{X,} \mathrm{Kassie} \mathrm{F} \mathrm{and} \mathrm{Mersch-Sundermann} \mathrm{V:} \mathrm{Induction} \mathrm{of}$ apoptosis in tumor cells by naturally occurring sulfur-containing compounds. Mutat Res 589: 81-102, 2005. PMID: 15795163. DOI: $10.1016 /$ j.mrrev.2004.11.001

12 Xiao D, Vogel V and Singh SV: Benzyl isothiocyanate-induced apoptosis in human breast cancer cells is initiated by reactive oxygen species and regulated by BAX and BAK. Mol Cancer Ther 5: 2931-2945, 2006. PMID: 17121941. DOI: 10.1158/ 1535-7163.MCT-06-0396

13 Herr I and Büchler MW: Dietary constituents of broccoli and other cruciferous vegetables: Implications for prevention and therapy of cancer. Cancer Treat Rev 36: 377-383, 2010. PMID: 20172656. DOI: 10.1016/j.ctrv.2010.01.002

14 Lamy E, Hertrampf A, Herz C, Schüler J, Erlacher M, Bertele D, Bakare A, Wagner M, Weiland T, Lauer U, Drognitz O, Huber R, Rohn S, Giesemann T and Mersch-Sundermann V: Preclinical evaluation of 4-methylthiobutyl isothiocyanate on liver cancer and cancer stem cells with different p53 status. PLoS One 8: e70846, 2013. PMID: 23936472. DOI: 10.1371/ journal.pone.0070846

15 Brown KK and Hampton MB: Biological targets of isothiocyanates. Biochim Biophys Acta 1810: 888-894, 2011. PMID: 21704127. DOI: 10.1016/j.bbagen.2011.06.004

16 Crampsie MA, Pandey MK, Desai D, Spallholz J, Amin S and Sharma AK: Phenylalkyl isoselenocyanates vs. phenylalkyl isothiocyanates: Thiol reactivity and its implications. Chem Biol Interact 200: 28-37, 2012. PMID: 22982772. DOI: 10.1016/ j.cbi.2012.08.022

17 Sharma AK, Sharma A, Desai D, Madhunapantula SV, Huh SJ, Robertson GP and Amin S: Synthesis and anticancer activity 
comparison of phenylalkyl isoselenocyanates with corresponding naturally occurring and synthetic isothiocyanates. J Med Chem 51: 7820-7826, 2008. PMID: 19053750. DOI: 10.1021/ jm800993r

18 Morse MA, Eklind KI, Hecht SS, Jordan KG, Choi CI, Desai DH, Amin SG and Chung FL: Structure-activity relationships for inhibition of 4-(methylnitrosamino)-1-(3-pyridyl)-1-butanone lung tumorigenesis by arylalkyl isothiocyanates in A/J mice. Cancer Res 51: 1846-1850, 1991. PMID: 2004368.

19 Jiao D, Eklind KI, Choi CI, Desai DH, Amin SG and Chung FL: Structure-activity relationships of isothiocyanates as mechanismbased inhibitors of 4-(methylnitrosamino)-1-(3-pyridyl)-1butanone-induced lung tumorigenesis in $\mathrm{a} / \mathrm{j}$ mice. Cancer Res 54: 4327-4333, 1994. PMID: 8044780

20 Lui VWY, Wentzel AL, Xiao D, Lew L, Singh SV and Grandis JR: Requirement of a carbon spacer in benzyl isothiocyanatemediated cytotoxicity and MAPK activation in head and neck squamous cell carcinoma. Carcinogenesis 24: 1705-1712, 2003. PMID: 12896907. DOI: 10.1093/carcin/bgg127

21 Franken NAP, Rodermond HM, Stap J, Haveman J and Bree CV: Clonogenic assay of cells in vitro. Nat Protoc 1: 2315-2319, 2006. PMID: 17406473. DOI: 10.1038/nprot.2006.339

22 Venning FA, Wullkopf L and Erler JT: Targeting ECM disrupts cancer progression. Front Oncol 5: 224, 2015. PMID: 26539408 DOI: $10.3389 /$ fonc. 2015.00224

23 Mi L, di Pasqua AJ and Chung FL: Proteins as binding targets of isothiocyanates in cancer prevention. Carcinogenesis 32: 1405-1413, 2011. PMID: 21665889. DOI: 10.1093/carcin/bgr111

$24 \mathrm{Xu} \mathrm{K}$ and Thornalley PJ: Involvement of glutathione metabolism in the cytotoxicity of the phenethyl isothiocyanate and its cysteine conjugate to human leukaemia cells in vitro. Biochem Pharmacol 61: 165-177, 2001. PMID: 11163331. DOI: 10.1016/ S0006-2952(00)00526-8

$25 \mathrm{Lu} \mathrm{L}$, Liu D, Ma X, Beklemishev A, Seiter K, Ahmed T and Chiao JW: The phenylhexyl isothiocyanate induces apoptosis and inhibits leukemia cell growth in vivo. Oncol Rep 16: 13631367, 2006. PMID: 17089062.

26 Huang S-H, Wu L-W, Huang A-C, Yu C-C, Lien J-C, Huang YP, Yang J-S, Yang J-H, Hsiao Y-P, Wood WG, Yu C-S and Chung J-G: Benzyl isothiocyanate (BITC) induces $\mathrm{G}_{2} / \mathrm{M}$ phase arrest and apoptosis in human melanoma A375.S2 cells through reactive oxygen species (ROS) and both mitochondria-dependent and death receptor-mediated multiple signaling pathways. J Agric Food Chem 60: 665-675, 2012. PMID: 22148415. DOI: $10.1021 / \mathrm{jf} 204193 \mathrm{v}$

27 Yu R, Mandlekar S, Harvey KJ, Ucker DS and Kong ANT: Chemopreventive isothiocyanates induce apoptosis and caspase3-like protease activity. Cancer Res 58: 402-408, 1998. PMID: 9458080 .
28 Guo Z, Smith TJ, Wang E, Eklind KI, Chung FL and Yang CS: Structure-activity relationships of arylalkyl isothiocyanates for the inhibition of 4-(methylnitrosamino)-1-(3-pyridyl)-1-butanone metabolism and the modulation of xenobiotic-metabolizing enzymes in rats and mice. Carcinogenesis 14: 1167-1173, 1993. 10.1093/carcin/bgg023. DOI: 10.1093/carcin/14.6.1167

29 Xiao D, Srivastava SK, Lew KL, Zeng Y, Hershberger P, Johnson CS, Trump DL and Singh SV: Allyl isothiocyanate, a constituent of cruciferous vegetables, inhibits proliferation of human prostate cancer cells by causing $\mathrm{G}_{2} / \mathrm{M}$ arrest and inducing apoptosis. Carcinogenesis 24: 891-897, 2003. PMID: 12771033. DOI: $10.1093 /$ carcin/bgg023

30 Crowley LC, Christensen ME and Waterhouse NJ: Measuring survival of adherent cells with the colony-forming assay. Cold Spring Harb Protoc, 2016. PMID: 27480717. DOI: 10.1101/ pdb.prot087171

31 Ma Y-S, Hsiao Y-T, Lin J-j, Liao C-L, Lin C-C and Chung J-G: Phenethyl isothiocyanate (PEITC) and benzyl isothiocyanate (BITC) inhibit human melanoma A375.S2 cell migration and invasion by affecting MAPK signaling pathway in vitro. Anticancer Res 37: 6223-6234, 2017. PMID: 29061805. DOI: 10.21873/anticanres.12073

32 Xiao D, Powolny AA, Moura MB, Kelley EE, Bommareddy A, Kim SH, Hahm ER, Normolle D, Van Houten B and Singh SV: Phenethyl isothiocyanate inhibits oxidative phosphorylation to trigger reactive oxygen species-mediated death of human prostate cancer cells. J Biol Chem 285: 26558-26569, 2010. PMID: 20571029. DOI: 10.1074/jbc.M109.063255

33 Liu KC, Huang YAT, Wu PP, Ji BC, Yang JS, Yang JL, Chiu TH, Chueh FUS and Chung JG: The roles of AIF and ENDO G in the apoptotic effects of benzyl isothiocyanate on DU145 human prostate cancer cells via the mitochondrial signaling pathway. Int J Oncol 38: 787-796, 2011. DOI: 10.3892/ijo.2010.894

34 Beklemisheva AA, Fang Y, Feng J, Ma X, Dai W and Chiao JW: Epigenetic mechanism of growth inhibition induced by phenylhexyl isothiocyanate in prostate cancer cells. Anticancer Res 26: 1225-1230, 2006. PMID: 16619528.

35 Tang L and Zhang Y: Mitochondria are the primary target in isothiocyanate- induced apoptosis in human bladder cancer cells. Mol Cancer Ther 4: 1250-1260, 2005. PMID: 16093441. DOI: 10.1158/1535-7163.MCT-05-0041

36 Navarro SL, Li F and Lampe JW: Mechanisms of action of isothiocyanates in cancer: An update. Food Funct 2: 579-587, 2011. PMID: 21935537. DOI: 10.1039/c1fo10114e.Mechanisms

Received January 25, 2019 Revised March 4, 2019 Accepted March 7, 2019 